\title{
Türkiye'nin En Uzun Sulama Tüneli Suruç Tünelinde Geoteknik ve Tahkimat Tasarımları
}

\author{
Celal AĞAN ${ }^{1}$ \\ Serkan ERTÜRK ${ }^{2}$
}

ÖZ

$\mathrm{Bu}$ çalışma Suruç ovasının sulanması amacıyla inşa edilen Suruç tüneli güzergahındaki geoteknik çalışmaları ve tünel destek tasarımını kapsamaktadır. Suruç tüneli (7.9 m kazı çapı), Türkiye'nin birinci, dünyanın ise beşinci en uzun sulama tüneli olacaktır $(17.2 \mathrm{~km})$. Tünel kireçtaşı ve marn birimlerinden geçmektedir. Saha çalışmaları sondaj, numune alımı, geçirgenlik deneyleri, laboratuvar testleri, kaya kütlesinin karakterize edilmesi (RMR, Q ve GSI sistemleriyle), süreksizlik ölçümleri ve kinematik analizleri kapsamaktadır. Kinematik analiz sonuçlarına göre kazı şevlerinde, tünel giriş ve çıkışında kayma riski olmadığı için daha detaylı şev duraylılık analizlerine gerek görülmemiştir. Tünel basınçları, yenilme zonu sınırları ve destek tasarımları ampirik, analitik ve sayısal yöntemlerle belirlenmiş, doğrulukları convergence-confinement yöntemiyle ve Plaxis 8.2 yazılımı ile sınanmıştır. Tünelin desteksiz, Q sisteminin önerdiği elemanlarla desteklendiği (kaya saplaması ve püskürtme beton destekli) ve önceden dökülmüş hazır betonla desteklendiği durumlar karşılaştırılmış, en küçük deformasyonlar önceden dökülmüş hazır beton destek elemanlarıyla $(0.90 \mathrm{~mm})$ elde edilmiştir.

Anahtar Kelimeler: Kaya kütlesi sinıflama yöntemleri, Hoek-Brown yenilme kriteri, Convergence-confinement yöntemi, sayısal analiz, tünel destek tasarımı, Suruç Tüneli.

\section{ABSTRACT \\ Geotechnical and Support Design of Suruç Tunnel, Turkey's Longest Irrigation Tunnel}

This research concerns with geotechnical and support designs along the Suruç tunnel, which will be used for irrigation of the Suruç Plain. The tunnel has a diameter of $7.9 \mathrm{~m}$. It will be the Turkey's 1st and the World's 5th longest irrigation tunnel $(17.2 \mathrm{~km})$. The tunnel runs through limestone and marly formations. Field studies include rock mass characterization (by using RMR, Q and GSI systems), discontinuity surveying, drilling, permeability tests and sampling. Support requirements were determined by using the rock

Not: Bu yaz1

- Yayın Kurulu'na 05.06.2014 günü ulaşmıştır.

- 30 Eylül 2017 gününe kadar tartışmaya açıktır.

- DOI: $10.18400 /$ tekderg.310455

1 Harran Üniversitesi, İnşaat Mühendisliği Bölümü, Şanlıurfa - agancelal@hotmail.com

2 Harran Üniversitesi, Yapı İşleri Daire Başkanlığı, Şanlıurfa - ser_erturk@hotmail.com 
Türkiye’nin En Uzun Sulama Tüneli Suruç Tünelinde Geoteknik ve Tahkimat Tasarımlar

mass classification systems, and evaluated by the convergence-confinement method and Plaxis 8.2 software. The minimum deformations $(0.90 \mathrm{~mm})$ occured in precast lining.

Keywords: Rock mass classification system, Hoek-Brown failure criterion, Convergence confinement method, numerical analyses, Tunnel support design, Suruç Tunnel.

\section{GíRIȘ}

Güneydoğu Anadolu Projesi (GAP), Türkiye'nin Güneydoğu Anadolu bölgesinde yaşayan 9 milyon kişinin [1] sürdürülebilir kalkınması amaçlı çok sektörlü bir bölgesel kalkınma projesidir. GAP'ın temel hedefleri tarım, sulama, hidroelektrik enerji üretimi, kentsel ve kırsal altyapı, ormancılık, eğitim ve sağlıktır. GAP'ın tamamlanmasıyla 1.82 milyon hektar alan sulamaya açllacak ve GAP kapsamında 22 baraj ve 19 hidroelektrik santralleri ve sulama şebekeleri hizmete girecektir. GAP'ın belkemiği olan Atatürk Barajı temelden 169 $\mathrm{m}$ yüksekliğe sahiptir. 84.5 milyon $\mathrm{m}^{3}$ dolgu hacmi ile dünyanın en büyük altıncı barajıdır. 1,2 milyon $\mathrm{m}^{2}$ enjeksiyon perdesine sahip dünyadaki en büyük yapıdır. Atatürk barajında iki adet $26.5 \mathrm{~km}$ uzunluğunda ve $7.62 \mathrm{~m}$ çapında sulama tüneli (Şanlıurfa Tünelleri) bulunmaktadır. Şanlıurfa tünelleri 1995 yılından beri çalışmakta olup amacı Urfa, Harran ve Ceylanpınar ovalarını (toplam $4763.7 \mathrm{~km}^{2}$ ) sulamaktır. Suruç ve Bozova ilçelerinin sulanması amacılya yapılmakta olan Suruç tüneli (7.9 m kazı çapı, $7 \mathrm{~m}$ tünel son kesit çapı), $17.2 \mathrm{~km}$ uzunluğu ile Türkiye'nin birinci dünyanın ise beşinci en uzun sulama tüneli olacaktır. Bu proje ile ekonomisi daha çok tarıma dayılı olan ve 1980'li yıllara kadar bereketli bir bölge olan Suruç ve Bozova ilçe merkezlerine bağl 105 yerleşim yerine ait toplam 94814 ha bereketli tarım arazisi suya kavuşacaktır. Suruç tüneli DSİ kontrolünde [1] tarafından tasarlanmış olup, tünel kazısı İlci Yapı Grubu tarafından yapılmaktadır.

Çalışma sahası MTA'nın 1/25 000 ölçekli topografik haritalarına göre N41-a1, N40-b2, N40-b3, N40-b4, N40-c1, N40-c2 and N40-c3 paftalarına düşmektedir. Tünel girişi Şanlıurfa'nın 40 km kuzeybatısında olup, Şanlıurfa-Gaziantep O-52 karayolundan ulaşım sağlanmaktadır (Şekil 1).

Bu çalı̧̧manın amac1; böylesine büyük bir ölçeğe ve öneme sahip Suruç tünelinin (i) tünel güzergahı boyunca karşılaşılabilecek kaya malzemelerinin ve kütlelerinin geoteknik ve mekanik parametrelerini tespit etmek, (ii) tünel giriş, çıkış ve kazı kesitlerinin şev duraylılık analizlerini yapmak ve (iii) üç farklı jeolojik birimden geçecek olan tünel için uygun destek tasarımı önermektir.

$\mathrm{Bu}$ amaçla, tünel güzergahı boyunca detaylı jeolojik, geoteknik ve kinematik incelemeler yapılmış, ayrıca sondaj, numune alımı, geçirgenlik deneyleri ve laboratuvar testleri yapılmıştır. Tünel giriş, çıkış ve kazı kesitlerinin şev duraylılık analizlerini yapmak için, Dips 2.2 yazılımı [2] kullanılarak kinematik analizler yapılmıştır. Kaya kütlesi sınıflandırmaları için uygun bulunan yüzleklere RMR, Q and GSI sınıflama sistemleri uygulanmıştır. Çeşitli araştırmacılar tarafından RMR, Q and GSI sınıflama sistemleri baz alınarak önerilen ampirik bağıntılarla, kaya kütlesinin dayanım parametreleri belirlenmiştir. Destek önerileri için Q sistemi kullanılmıştır. Daha sonra, deformasyonlar, gerilme konsantrasyonları ve tünel çevresindeki gevşeme zonu kalınlığı convergence-confinement yöntemiyle çözümlemeli olarak, Plaxis 8.2 [3] yazılımıyla sayısal olarak irdelenmiştir. Son olarak, önerilen destek sistemlerinin performansı değerlendirilmiştir. 
Celal AĞAN, Serkan ERTÜRK
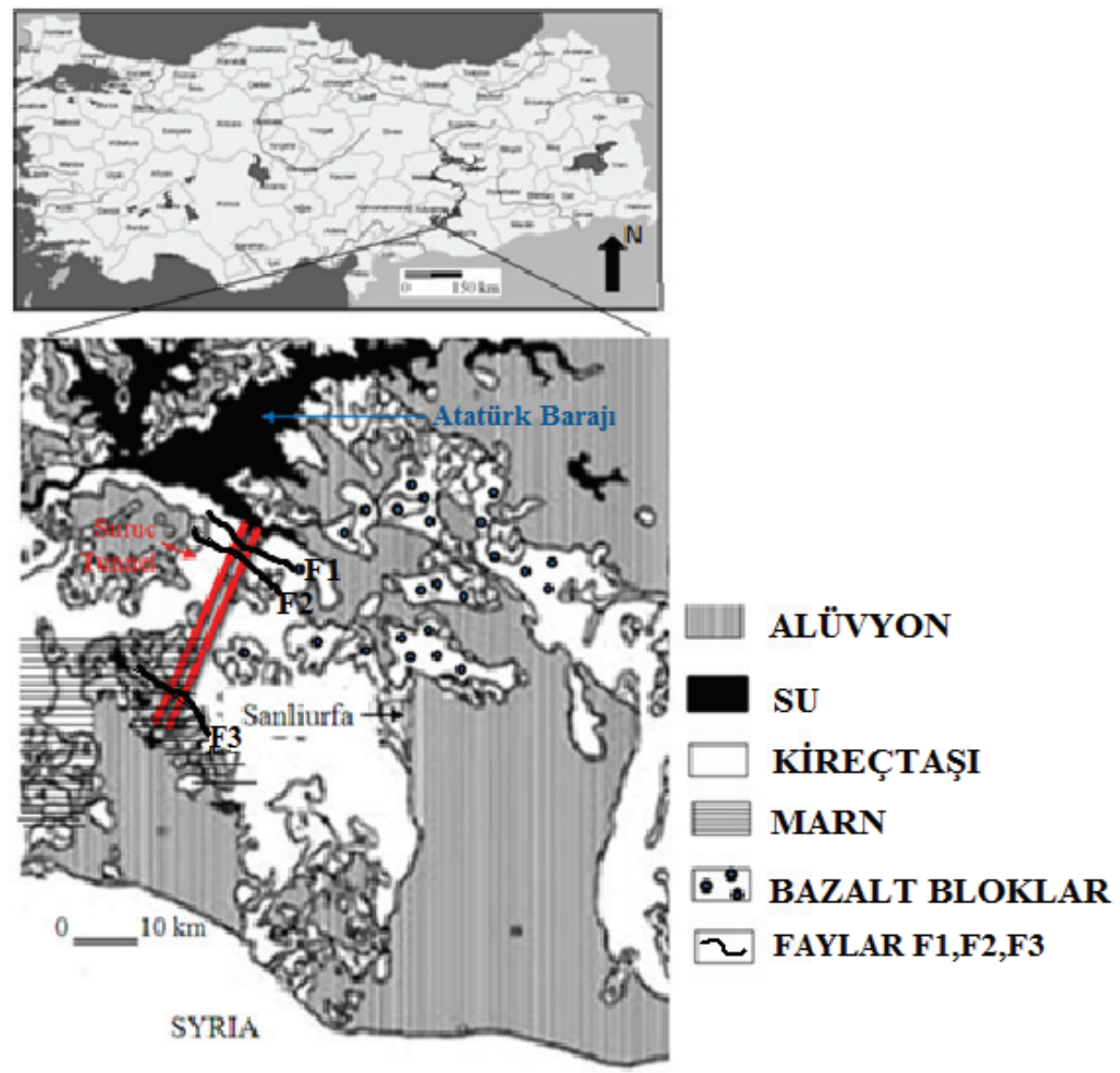

Şekil 1. Suruç tüneli konum ve jeolojik haritası

\section{JEOLOJi}

Tünel jeolojik koşullarının bilinmesi kazı yöntemi, uygun malzeme, ekipman ve destek tipi belirlenmesi açısından önemlidir. Ayrıca, inşaat maliyeti ve jeolojik koşulların aydınlatılamadığı yerlerde ki bazı projelerde iyileştirme maliyeti orijinal bütçeyi fazlasıyla aşmaktadır [4].

$17.2 \mathrm{~km}$ uzunluğunda planlanan Suruç tüneli kireçtaşı ve marn birimlerinden oluşan Gaziantep birimi içerisinde kazılmaktadır. Güzergahın 8.1 km'si kireçtaşı ve 9.1 km'si marn birimlerinden geçmektedir. Gaziantep birimi, ince-orta tabakalı, yer yer kalın tabakalı, açık gri, bej, beyaz, açık kahve renklerde kırılgan, yer yer marn ara seviyeli killi kireçtaşlarından oluşur. Suruç tünelinde en fazla örtü kalınlığı marnda $80 \mathrm{~m}$ ve kireçtaşında 50 m'dir.

Güzergahın bazı kısımlarında yüzeyde alüvyon ve yamaç molozundan oluşan Kuvaterner çökelleri görülmektedir. Alüvyon, Birleştirilmiş Zemin Sınıflandırma Sistemine [5] göre 
Türkiye’nin En Uzun Sulama Tüneli Suruç Tünelinde Geoteknik ve Tahkimat Tasarımlar

SW-SP olarak sınıflandırılır ve çakıl, kum, silt ve kil ve düzgün taneli malzemelerden oluşur. Sondaj sonuçlarına göre alüvyonun kalınlığı en fazla 10 m'dir. Yamaç molozu CLML olarak sınıflandırılır ve ince taneli çakıl, kum ve siltli kilden oluşmaktadır. Sondaj sonuçlarına göre yamaç molozunun kalınlığı en fazla 2 m'dir (Şekil 2).

Çalışma alanında üç adet KB-GD doğrultulu fay gözlenmiştir (Şekil 2). Arap plakasının Anadolu plakasını itmesiyle oluşan bu kırıklar, $580 \mathrm{~km}$ uzunluğuyla Doğu Anadolu fay zonu Türkiye'nin en önemli tektonik özelliklerinden biridir. Faylar Suruç tünelinin $0.3 \mathrm{~km}$, $2.1 \mathrm{~km}$ ve $16.2 \mathrm{~km}$ 'sinde görülecektir (Şekil 2). Birinci ve üçüncü faylar normal fay, ikinci fay ise ters faydir.

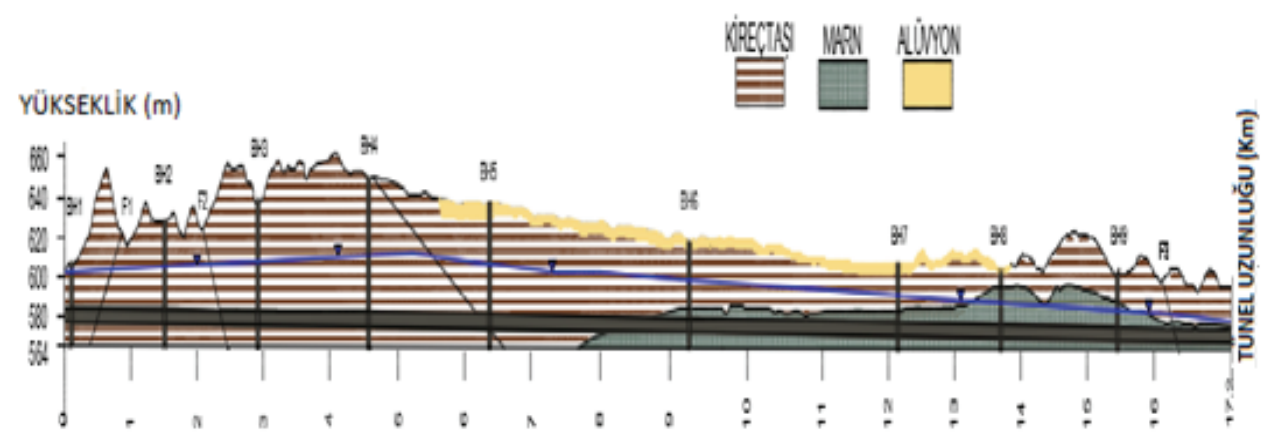

Şekil 2. Tünel güzergahının boyuna jeolojik kesiti ve sondaj kuyularının yerleri

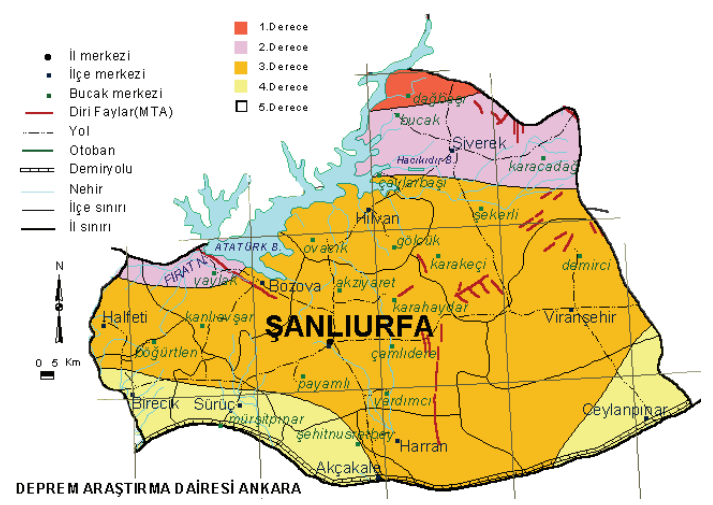

Şekil 3.

Bu bölge [6] tarafindan hazırlanan Türkiye deprem haritasına göre kısmen 3. ve kısmen de 4. derece deprem bölgesi içinde yer almaktadır (Şekil 3). 


\section{GEOTEKNIK İNCELEMELER}

Suruç tüneli kireçtaşı, marn ve fay zonu olmak üzere üç ayrı birime ayrılmış ve her birimin geoteknik özellikleri ayrı ayrı incelenmiştir. Geoteknik incelemeler ve kaya mekaniği çalışmaları süreksizlik ölçümleri, kinematik analizler, sondaj, geçirgenlik testleri ve laboratuvar testlerini ihtiva etmektedir.

\subsection{Süreksizlik ölçümleri, kinematik analizler}

Süreksizliklerin aralığı, açıklı̆̆ı, devamlılığı ve yönelimleri gibi özellikleri kaya kütlesinin özelliklerini doğrudan etkilemektedir. Bu süreksizlik özellikleri [7] standartlarına uygun olarak yerinde tespit edilmiştir. Tünel güzergahında ölçülen 75 süreksizlik ölçümüyle 1 hakim (baskın) eklem seti tespit edilmiştir. Ayrıca, tünel girişleri, kazı kesitleri ve kaya tabakalarının doğrultu ve eğim açları ölçülmüştür. Jeolojik birimlere ait içsel sürtünme açıları da girdi olarak kullanmak üzere kinematik analize dahil edilmiştir.

Hakim (dominant) eklem seti; $D: \mathrm{N} 45^{\circ} \mathrm{W} / 80^{\circ} \mathrm{NE}$

Tabakalaşma (stratification); $\mathrm{S}: \mathrm{N} 30^{\circ} \mathrm{E} / 12^{\circ} \mathrm{SE}$

Tünel giriş $\left(\mathrm{P}_{\mathrm{E}}\right)$ ve çıkış $\left(\mathrm{P}_{\mathrm{O}}\right)$ portalları; $\mathrm{P}_{\mathrm{E}}: \mathrm{N} 75^{\circ} \mathrm{W} / 55^{\circ} \mathrm{NE}, \mathrm{P}_{\mathrm{O}}: \mathrm{N} 75^{\circ} \mathrm{W} / 55^{\circ} \mathrm{SW}$

; $\mathrm{C}_{\mathrm{L}}: \mathrm{N} 15^{\circ} \mathrm{E} / 55^{\circ} \mathrm{NW}, \mathrm{C}_{\mathrm{R}}: \mathrm{N} 15^{\circ} \mathrm{E} / 55^{\circ} \mathrm{SE}$

Kireçtaşı $\left(\varnothing_{\mathrm{L}}\right)$ ve marn $\left(\emptyset_{\mathrm{M}}\right)$ en düşük içsel sürtünme açıları; $\emptyset_{\mathrm{L}}: 25^{\circ}, \emptyset_{\mathrm{M}}: 15^{\circ}$

$\mathrm{Bu}$ ölçümler eşit alanlı stereografik çizime dayalı Dips 2.2 yazılımı [2] ile değerlendirilmiştir. Kazı şevlerinde, tünel giriş ve çıkışında herhangi bir düzlemsel ve kama tipi kayma riski tespit edilmemiş̧tir (Şekil 3). Bu nedenle Kazı kesitleri sol $\left(C_{L}\right)$ ve sağ $\left(C_{R}\right)$ yamaçlar, daha detaylı şev duraylılık analizlerine gerek görülmemiştir.
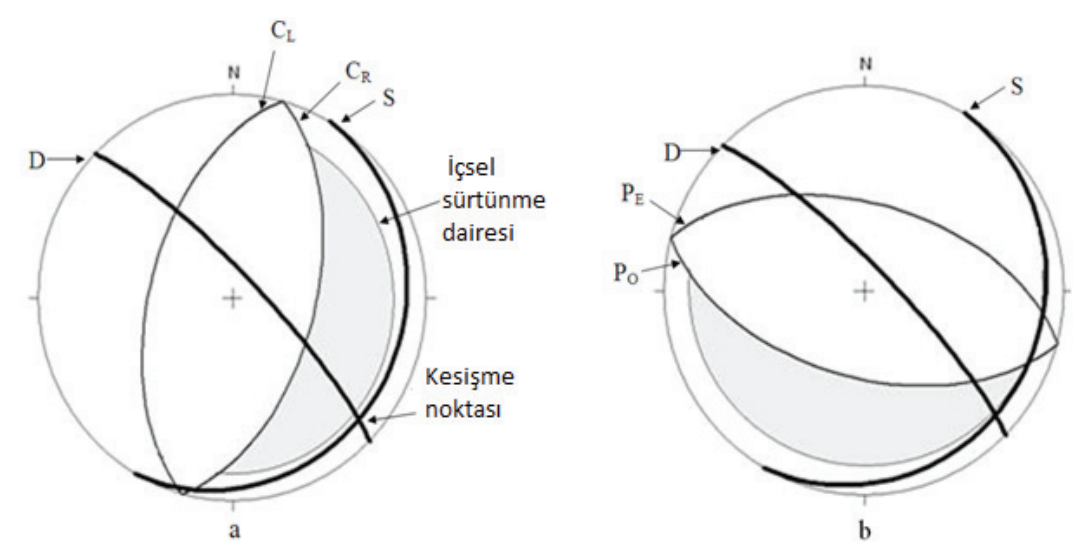

Şekil 4. (a) Kazı kesitleri sol $\left(C_{L}\right)$ ve sağ $\left(C_{R}\right)$ yamaçlarda ve (b) tünel giriş $\left(P_{E}\right)$ ve çılklş $\left(P_{O}\right)$ portallarında kinematik analizler 
Ölçülebilen 75 adet eklem ve tabakaların kutup dağılım şekli ve kontur diyagramı Şekil 4 'de sunulmuştur.

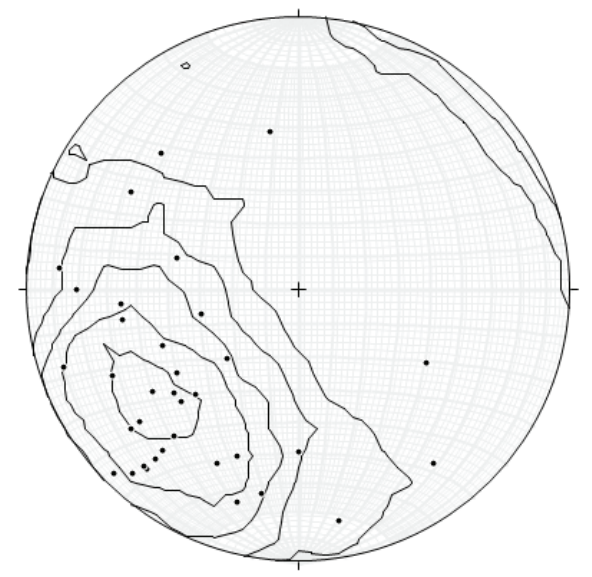

Şekil 5. Ölçülebilen 75 adet eklem ve tabakaların kutup dağılım şekli ve kontur diyagramı

\subsection{Sondaj}

Tünel güzergahı boyunca litolojinin belirlenmesi, temel kayaç koşullarının daha iyi anlaşılması, yeraltı su seviyesinin (YASS) ölçülmesi ve geçirgenlik deneylerinin yapılması amacıyla toplam $530 \mathrm{~m}$ uzunluğunda 10 adet sondaj kuyusu DSİ tarafindan açılmış (SK-1, SK-2, SK-3, ... SK-10) ve laboratuvar testleri için bu kuyulardan karot numune alınmıştır (Şekil 2). Ayrıca, her bir sondaj kuyusu için kaya kalite değeri (RQD, $10 \mathrm{~cm}$ veya daha fazla uzunluklarda sondaj karotu yüzdesi), toplam karot verimi (TKV, sondaj deliği karot verimi yüzdesi) ve jeolojik birimlerin Lugeon cinsinden geçirgenlik değerleri belirlenmiş ve Tablo 1'de özetlenmiştir.

\subsection{Geçirgenlik testleri}

Sondajlar sırasında toplam 51 adet basınçlı su testi yapılmış ve bu birimlerin geçirgenlikleri Lugeon değerleri olarak tespit edilmiştir.

Tablo 1'deki veriler incelendiğinde, düşük kaya kalitesi ile geçirgenliğin arttığ1 görülmektedir. Ancak, geçirgenlik ve derinlik arasında hiç bir bağıntı tespit edilememiştir. Lugeon sonuçlarına göre kireçtaşı geçirgen, marn ise geçirimsiz olarak sınıflandırılmıştır. Tünelin kireçtaşı içerisinde kazıldığı bölümlerde, su sızıntılarını önlemek için mutlaka enjeksiyon yapılmalıdır. 
Tablo 1. Sondajlardan elde edilen geoteknik parametreler [1]

\begin{tabular}{|c|c|c|c|c|c|c|c|c|c|c|c|c|}
\hline \multirow{2}{*}{ 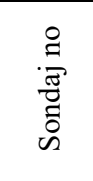 } & \multirow{2}{*}{ 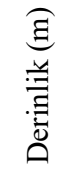 } & \multirow[b]{2}{*}{ 声 } & \multirow{2}{*}{$\begin{array}{l}\underset{\Xi}{\Xi} \\
\text { 足 } \\
\lambda\end{array}$} & \multicolumn{3}{|c|}{ RQD (\%) } & \multicolumn{3}{|c|}{ TKV (\%) } & \multicolumn{3}{|c|}{ Lugeon } \\
\hline & & & & $\min$ & mak & ort & $\min$ & mak & ort & $\min$ & mak & ort \\
\hline SK-1 & 38 & Kireçtaş1 & - & 0 & 95 & 30 & 60 & 100 & 85 & 1.2 & 3.4 & 2.0 \\
\hline SK-2 & 58 & Kireçtaş1 & - & 0 & 85 & 29 & 30 & 100 & 70 & 2.4 & 7.8 & 4.7 \\
\hline SK-3 & 70 & Kireçtaş1 & 32 & 15 & 85 & 50 & 60 & 100 & 87 & 2.3 & 2.8 & 2.5 \\
\hline SK-4 & 81 & Kireçtaş1 & 38 & 0 & 85 & 55 & 35 & 100 & 85 & 2.1 & 3.6 & 2.6 \\
\hline SK-5 & 70 & Kireçtaş1 & 32 & 0 & 90 & 22 & 15 & 100 & 71 & 4.6 & 8.3 & 6.1 \\
\hline SK-6 & 53 & $\begin{array}{l}36 \mathrm{~m} \text { kireçtaş1 } \\
\mathbf{1 7} \mathbf{~ m} \text { marn }\end{array}$ & 23 & $\begin{array}{c}0 \\
10\end{array}$ & $\begin{array}{l}43 \\
90\end{array}$ & $\begin{array}{c}9 \\
33\end{array}$ & $\begin{array}{l}30 \\
45\end{array}$ & $\begin{array}{l}65 \\
95\end{array}$ & $\begin{array}{l}48 \\
70\end{array}$ & $\begin{array}{c}- \\
0.1\end{array}$ & $\begin{array}{c}- \\
0.7\end{array}$ & 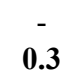 \\
\hline SK-7 & 43 & $\begin{array}{l}26 \mathrm{~m} \text { kireçtaş1 } \\
\mathbf{1 7} \mathbf{~ m} \text { marn }\end{array}$ & 17 & $\begin{array}{l}15 \\
\mathbf{1 0}\end{array}$ & $\begin{array}{l}70 \\
85\end{array}$ & $\begin{array}{l}41 \\
48\end{array}$ & $\begin{array}{l}65 \\
\mathbf{6 5}\end{array}$ & $\begin{array}{l}100 \\
95\end{array}$ & $\begin{array}{l}80 \\
82\end{array}$ & $\begin{array}{c}- \\
0.1\end{array}$ & - & - \\
\hline SK-8 & 42 & $\begin{array}{l}11 \mathrm{~m} \text { kireçtaş1 } \\
\mathbf{3 1} \mathbf{~ m} \text { marn }\end{array}$ & 16 & $\begin{array}{l}0 \\
\mathbf{0}\end{array}$ & $\begin{array}{c}0 \\
90\end{array}$ & $\begin{array}{c}0 \\
60\end{array}$ & $\begin{array}{l}15 \\
40\end{array}$ & $\begin{array}{c}50 \\
100\end{array}$ & $\begin{array}{l}33 \\
84\end{array}$ & $\begin{array}{l}- \\
0.1\end{array}$ & $\begin{array}{c}- \\
0.3\end{array}$ & - \\
\hline SK-9 & 42 & $\begin{array}{l}16 \text { m kireçtaş } 1 \\
\mathbf{2 6} \mathbf{~ m} \text { marn }\end{array}$ & 16 & $\begin{array}{l}10 \\
\mathbf{5 0}\end{array}$ & $\begin{array}{l}30 \\
85\end{array}$ & $\begin{array}{l}16 \\
70\end{array}$ & $\begin{array}{l}33 \\
90\end{array}$ & $\begin{array}{c}75 \\
100\end{array}$ & $\begin{array}{l}59 \\
97\end{array}$ & $\overline{-}-$ & $\begin{array}{c}- \\
0.52\end{array}$ & $\begin{array}{c}- \\
0.31\end{array}$ \\
\hline SK-10 & 31 & $\begin{array}{l}10 \text { m kireçtaş } 1 \\
\mathbf{2 1} \mathbf{~ m ~ m a r n ~}\end{array}$ & 14 & $\begin{array}{l}0 \\
\mathbf{0}\end{array}$ & $\begin{array}{l}17 \\
95\end{array}$ & $\begin{array}{l}10 \\
30\end{array}$ & $\begin{array}{l}25 \\
\mathbf{2 5}\end{array}$ & $\begin{array}{c}70 \\
100\end{array}$ & $\begin{array}{l}54 \\
66\end{array}$ & $\begin{array}{c}- \\
0.16\end{array}$ & $\begin{array}{c}- \\
0.77\end{array}$ & 0.49 \\
\hline
\end{tabular}

\subsection{Laboratuvar test sonuçları}

Sondajlardan alınan 77 adet numune [7] standartlarına uygun olarak DSİ laboratuvarlarında test edilmiş, kaya numunelerine ait birim ağırlık, tek eksenli basınç dayanımı (UCS), Elastisite modülü ve Poisson oranı belirlenmiştir. Direk kesme kutusu deneyiyle kohezyon ve içsel sürtünme açıları belirlenmiştir. Bu verilere sayısal analizlerde girdi parametreleri olarak da ihtiyaç vardır. Sonuçlar Tablo 2'de sunulmuştur.

Tablo 2. Laboratuvar test sonuçları [1]

\begin{tabular}{|c|c|c|c|c|c|c|}
\hline \multirow{2}{*}{ Parametreler } & \multicolumn{3}{|c|}{ Kireçtaş1 } & \multicolumn{3}{|c|}{ Marn } \\
\hline & $\min$ & ort & mak & $\min$ & ort & mak \\
\hline Kohezyon (MPa) & 2.3 & 4.0 & 5.2 & 3.1 & 3.5 & 3.9 \\
\hline Içsel sürtünme açısı $\left(^{\circ}\right)$ & 25.0 & 30.0 & 36.0 & 15.0 & 22.0 & 30.0 \\
\hline Birim ağırlık $\left(\mathrm{kN} / \mathrm{m}^{3}\right)$ & 19.8 & 23.0 & 24.2 & 19.3 & 23.1 & 24.9 \\
\hline Tek eksenli basınç dayanımı (MPa) & 4.1 & 20.0 & 44.0 & 2.0 & 8.1 & 13.5 \\
\hline Elastisite modülü (GPa) & 2.5 & 9.0 & 15.1 & 1.0 & 3.2 & 5.7 \\
\hline Poison oran1 & 0.15 & 0.20 & 0.25 & 0.24 & 0.30 & 0.38 \\
\hline
\end{tabular}




\section{KAYA KÜTLESININ KARAKTERIZE EDILMESI}

Kaya kütlesinin doğru karakterize edilmesi tünel tasarımının, kazı yönteminin, destek türünün doğru seçilmesi açısından önemli bir jeolojik faktördür. Kaya kütlesi karakterize etme çalışmaları sondaj verileri de kullanılarak, mevcut yüzleklerde ve yamaçlardaki kaya yüzeylerinde yapılmıştır.

Günümüze kadar araştırmacılar tarafından birçok kaya kütle sınıflandırma sistemi geliştirilmiştir [8]. Ancak, kireçtaşı ve marn birimlerini karakterize etme çalışmaları için en çok bilinen yöntemler olan, RQD [9] , RMR [10], Q [11], RMİ [12] ve GSI [13] yöntemleri kullanılmıştır. Tercihen, modifiye edilmiş versiyonların RMR [14], Q [15] ve GSI [16-18], kullanımına özen gösterilmiştir. Sınıflandırma sistemleriyle elde edilmiş en yüksek (mak), en düşük (min) ve ortalama (ort) değerler tablolar halinde sunulmuştur.

RMR sisteminin girdileri UCS, RQD, süreksizlik aralığı, süreksizlik koşulları, yeraltı suyu koşulları ve süreksizlik yönelimidir. RMR tahminlerin özeti Tablo 3'de sunulmuştur.

Tablo 3. RMR çalışmasının girdileri ve sonuçları

\begin{tabular}{|c|c|c|c|c|c|c|c|c|}
\hline Birim & & $\begin{array}{c}\mathrm{UCS} \\
(\mathrm{MPa})\end{array}$ & $\begin{array}{l}\text { RQD } \\
(\%)\end{array}$ & $\begin{array}{l}\text { Süreksizli } \\
\text { k aralığ1 } \\
(\mathrm{mm})\end{array}$ & $\begin{array}{c}\text { Süreksizlik } \\
\text { yüzeylerini } \\
\text { n durumu }\end{array}$ & $\mathrm{Su}$ & $\begin{array}{c}\text { Eklem } \\
\text { uyum } \\
\text { derecesi }\end{array}$ & $\begin{array}{c}\text { RMR } \\
\text { değerleri }\end{array}$ \\
\hline \multirow{3}{*}{ Kireçtaş1 } & $\min$ & 4.1 & 0 & 60 & \multirow{6}{*}{ 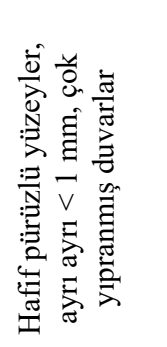 } & \multirow{3}{*}{ 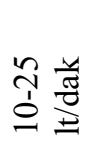 } & \multirow{6}{*}{$\begin{array}{l}\vec{\Xi} \\
\stackrel{\Xi}{\Xi}\end{array}$} & 34 \\
\hline & ort & 20 & 40 & 200 & & & & 43 \\
\hline & mak & 44 & 95 & 2000 & & & & 69 \\
\hline \multirow{3}{*}{ Marn } & $\min$ & 2 & 0 & 60 & & \multirow{3}{*}{ 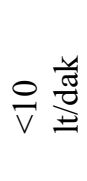 } & & 37 \\
\hline & ort & 8.1 & 65 & 500 & & & & 49 \\
\hline & mak & 13.5 & 95 & 2000 & & & & 71 \\
\hline Fay & & 1 & 0 & 10 & & & $\begin{array}{c}\text { Çok } \\
\text { olumsuz }\end{array}$ & 15 \\
\hline
\end{tabular}

RMR sistemi gerilme parametrelerinden yoksun olduğundan, kaya kütlesini karakterize etme çalışmaları Q sistemiyle de yapılmıştır. Q sisteminin girdileri RQD, çatlak seti sayısı $(\mathrm{Jn})$, çatlak pürüzlülük (Jr), eklem değişiklikleri (Ja), çatlak su indirgeme faktörü (JW) ve gerilme indirgeme faktörüdür (SRF).

Kaya kütlelerin Q değerlerini hesaplamak için aşağıdaki eşitlik kullanılır.

$\mathrm{Q}=(\mathrm{RQD} / \mathrm{Jn}) \cdot(\mathrm{Jr} / \mathrm{Ja}) \cdot(\mathrm{Jw} / \mathrm{SRF})$

[19] Q'nun gerilmeden serbest hali olan $Q_{N}$ 'i aşağıdaki denklem ile ifade etmektedir. $Q_{N}$ hesaplamak için SRF'nin 1 olduğu varsayılır. 
$\mathrm{Q}_{\mathrm{N}}=(\mathrm{RQD} / \mathrm{Jn}) \cdot(\mathrm{Jr} / \mathrm{Ja}) \cdot(\mathrm{JW})$

[20] tünel kalite indeksini $Q^{\prime}$ olarak güncellemiş ve aşağıdaki denklemle bulmayı önermiştir. Q' hesaplamak amacıyla, Jw'nin 1 olduğu varsayllır. Böylece, Denklem 2 aşağıdaki hali alır.

$\mathrm{Q}^{\prime}=(\mathrm{RQD} / \mathrm{Jn})$. (Jr/Ja)

Son olarak, [21] Q sistemi güncelleyerek $Q_{c}$ parametresini önermiştir. Aşağıdaki denklem yeni bir parametre ile mevcut mühendislik parametreleri arasındaki bağıntıların belirlenmesi amacıyla önerilmiştir. $\sigma_{\mathrm{ci}}$ bozulmamış kayanın UCS değeridir.

$\mathrm{Q}_{\mathrm{C}}=\mathrm{Q} \cdot\left(\sigma_{\mathrm{ci}} / 100\right)$

Q tahminlerinin özeti Tablo 4'de sunulmuştur.

Tablo 4. $Q$ çalışmasının girdileri ve sonuçları

\begin{tabular}{ccccccccccccc}
\multirow{2}{*}{ Birim } & & $\begin{array}{c}\sigma_{\mathrm{ci}} \\
\mathrm{MP}\end{array}$ & $\begin{array}{c}\mathrm{RQD} \\
\mathrm{a}\end{array}$ & $\mathrm{Jn}$ & $\mathrm{Jr}$ & $\mathrm{Ja}$ & $\mathrm{JW}$ & $\mathrm{SRF}$ & $\mathbf{Q}$ & $\mathrm{Q}_{\mathrm{N}}$ & $\mathrm{Q}^{\prime}$ & $\mathrm{Q}_{\mathrm{C}}$ \\
\hline \multirow{3}{*}{ Kireçtaş1 } & $\mathrm{min}$ & - & - & - & - & - & - & - & $\mathbf{0 . 0 3}$ & - & - & - \\
& ort & 20 & 40 & 6 & 3 & 2 & 0.66 & 5 & $\mathbf{1 . 3}$ & 6.6 & 9.8 & 0.26 \\
& $\mathrm{mak}$ & - & - & - & - & - & - & - & $\mathbf{3 . 1}$ & - & - & - \\
\hline \multirow{2}{*}{ Marn } & min & - & - & - & - & - & - & - & $\mathbf{0 . 0 2}$ & - & - & - \\
& ort & 8.1 & 65 & 6 & 3 & 6 & 1 & 5 & $\mathbf{1 . 1}$ & 5.4 & 5.5 & 0.09 \\
& mak & - & - & - & - & - & - & - & $\mathbf{1 . 6}$ & - & - & - \\
\hline \multirow{2}{*}{ Fay } & & 1.0 & 15 & 6 & 0.5 & 8 & 0.33 & 10 & $\mathbf{0 . 0 0 5 2}$ & 0.0 & 0.2 & 0.0005
\end{tabular}

Son olarak, kaya kütlesinin karakterize edilmesi GSI sistemi tarafından yapılmıştır. Rr (pürüzlülük derecesi), Rw (bozunma derecesi), Rf (dolgu derecesi), SCR (yüzey koşulları derecesi), Sx (x yönünde süreksizlik sayısı), Sy (y yönünde süreksizlik sayıs1), Sz (z yönünde süreksizlik sayısı), Jv (hacimsel eklem sayısı) ve SR (yapısal derece) parametrelerinin seçimi için [17]'nin önerileri takip edilmiştir. Çünkü çalışma sahasında üç eksenli yüzler ile Jv değerlerinin belirlenmesi için bazı uygun yüzlekler tespit edilmiştir.

Ayrıca, [18] tarafından yakın zamanda güncellenmiş GSI grafiği, GSI değerlerinin değerlendirilmesi için kullanılmıştır. GSI tahminlerinin bir özeti Tablo 5'de sunulmuştur.

Farklı birimler için GSI değerlerinin aralıkları [18] tarafından önerilen GSI grafiğine işlenmiş ve Şekil 4'de sunulmuștur. Kireçtaşı ve marn için GSI'nin en yüksek, en düşük ve ortalama değerleri birbirine oldukça yakındır. Bütün birimler için kesişen GSI değerleri tarandığında, 25-62 arasında değişen tüm GSI değerlerinin bütün tünel güzergahını temsil edebileceği yorumu yapılmıştır. 
Türkiye 'nin En Uzun Sulama Tüneli Suruç Tünelinde Geoteknik ve Tahkimat Tasarımlar

Tablo 5. GSI çalışması girdileri ve sonuçları

\begin{tabular}{|c|c|c|c|c|c|c|c|c|c|}
\hline Birim & & $\mathrm{Rr}$ & $\mathrm{Rw}$ & $\mathrm{Rf}$ & SCR & $\mathrm{Sx}, \mathrm{Sy}, \mathrm{Sz} *(\mathrm{~cm})$ & $\mathrm{Jv}$ & SR & GSI \\
\hline \multirow{3}{*}{ Kireçtaşı } & $\min$ & 1 & 3 & 2 & 6 & $2,20,25$ & 1000 & 5 & 23 \\
\hline & ort & 3 & 5 & 4 & 12 & $15,40,100$ & 17 & 18 & 42 \\
\hline & mak & 5 & 6 & 6 & 17 & $50,60,200$ & 2 & 66 & 74 \\
\hline \multirow{3}{*}{ Marn } & $\min$ & 1 & 2 & 2 & 5 & $2,20,35$ & 715 & 8 & 22 \\
\hline & ort & 1 & 3 & 2 & 6 & $15,50,150$ & 9 & 52 & 39 \\
\hline & mak & 3 & 5 & 4 & 12 & $100,100,200$ & 1 & 80 & 68 \\
\hline Fay & & 1 & 1 & 2 & 4 & $2,5,10$ & 10000 & $\mathbf{0}$ & 16 \\
\hline
\end{tabular}

* süreksizlik aralı̆̆ in $x, y, z$ eksenleri

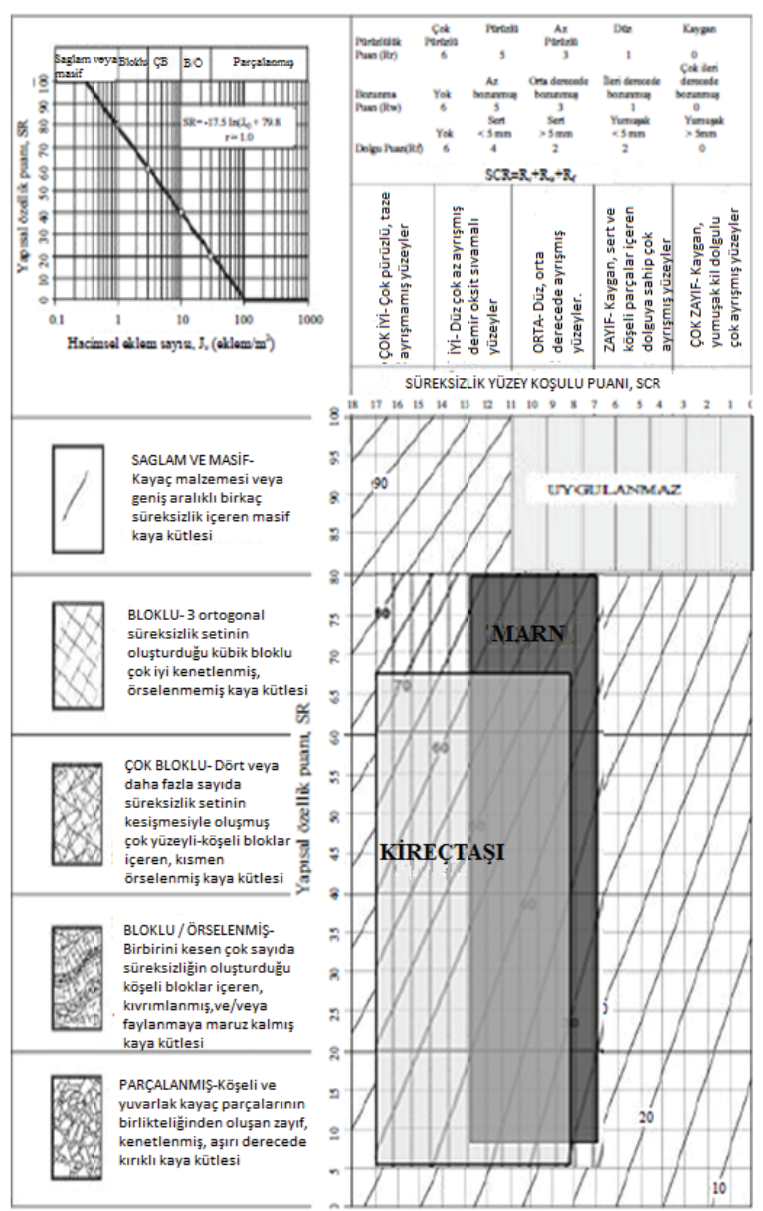

Şekil 6. GSI değerleri ve aralıkları (Sonmez ve Ulusay, 2002) 


\section{KAYA KÜTLESI PARAMETRELERİ}

Suruç tünel güzergahındaki kaya kütlelerinin dayanım özellikleri RMR, Q, GSI ve UCS değerlerini kullanan Hoek-Brown'un ampirik yenilme kriteri [20] ile belirlenmiştir. Ayrıca, geomekanik kalite göstergeleri olan RMR, Q ve GSI değerleri kullanılarak, kireçtaşı ve marn birimlerine ait deformasyon modülleri dolaylı olarak belirlenmiştir.

\subsection{Hoek-Brown kaya kütlesi sabitleri}

$\mathrm{m}_{\mathrm{i}}, \mathrm{m}_{\mathrm{b}}, \mathrm{s}$ ve a kaya kütlesi sabitleri, [20] tarafından önerilen ve aşağıda verilen formüller kullanılarak tespit edilmiştir. Sağlam kaya sabiti $\mathrm{m}_{\mathrm{i}}$ [20] önerilerine göre kireçtaşı için 10 ve marn için 8 seçilmiştir. D kaya kütlesinin kazısının örselenme faktörü olarak ifade edilmektedir. Tam kesit TBM kazı sırasında çok az örselemeye neden olduğundan D bu çalışmada sıfır olarak kabul edilmiştir.

$\mathrm{m}_{\mathrm{b}} / \mathrm{m}_{\mathrm{i}}=\exp [(\mathrm{GSI}-100) /(28-14 . \mathrm{D})]$

Eger, GSI $<25$

$\mathrm{s}=0$

$\mathrm{a}=0.65-(\mathrm{GSI} / 200)$

Eğer, GSI $>25$

$\mathrm{s}=\exp [(\mathrm{GSI}-100) / 9]$

$\mathrm{a}=0.5$

[22] tünelde $m_{b}$ ve s sabitlerini hesaplamak için 10 numaralı denklemi önermiştir.

$\mathrm{m}_{\mathrm{b}} / \mathrm{m}_{\mathrm{i}}=0.135 \cdot\left(\mathrm{Q}_{\mathrm{N}}\right)^{1 / 3}$

$\mathrm{S}=0.002 \cdot \mathrm{Q}_{\mathrm{N}}$

[23]'de $m_{b}$ ve s sabitlerini hesaplamak için aşağıdaki denklemleri önermiştir. [24]'ün açıkladığı kaya kütlesinin eklemlenme parametresi (Jp) kireçtaşı için 0,2 ve marn için ise 0.3 olarak girilmiştir.

$$
\begin{array}{ll}
\mathrm{m}_{\mathrm{b}}=\mathrm{m}_{\mathrm{i}} \cdot(\mathrm{Jp})^{0.64} & \text { (örselenmiş kayalar için ) } \\
\mathrm{m}_{\mathrm{b}}=\mathrm{m}_{\mathrm{i}} \cdot(\mathrm{Jp})^{0.875} & \text { (örselenmemiş kayalar için) } \\
\mathrm{s}=(\mathrm{Jp})^{2} &
\end{array}
$$

Hesaplanan kaya kütlesi sabitleri olan $m_{b}, m_{i}$, a ve s değerleri Tablo 6'da sunulmuştur. 
Türkiye'nin En Uzun Sulama Tüneli Suruç Tünelinde Geoteknik ve Tahkimat Tasartmlar

Tablo 6. Tünel güzergahı boyunca hesaplanan kaya kütlesi parametreleri

\begin{tabular}{|c|c|c|c|c|c|c|c|}
\hline \multirow{2}{*}{ Parametre } & \multirow{2}{*}{$\begin{array}{l}\text { Denklem } \\
\text { No }\end{array}$} & \multicolumn{3}{|c|}{ Kireçtaş1 } & \multicolumn{3}{|c|}{ Marn } \\
\hline & & $\min$ & ort & mak & $\min$ & ort & mak \\
\hline $\mathrm{m}_{\mathrm{i}}$ & & 10 & 10 & 10 & 8 & 8 & 8 \\
\hline \multirow[t]{3}{*}{$\mathrm{m}_{\mathrm{b}}$} & 5 & 0.64 & 1.26 & 3.95 & 0.49 & 0.91 & 2.55 \\
\hline & 10 & - & 2.38 & - & - & 2.18 & - \\
\hline & 12 & - & 3.56 & - & - & 3.70 & - \\
\hline Ortalama & & & 2.40 & & & 2.26 & \\
\hline \multirow[t]{4}{*}{$\mathrm{S}$} & 8 & - & 0.0016 & 0.056 & - & 0.0011 & 0.029 \\
\hline & 6 & 0 & - & - & 0 & - & - \\
\hline & 11 & - & 0.013 & - & - & 0.011 & - \\
\hline & 14 & - & 0.04 & - & - & 0.09 & - \\
\hline Ortalama & & & 0.018 & & & 0.034 & \\
\hline \multirow[t]{2}{*}{ A } & 9 & - & 0.5 & 0.5 & - & 0.5 & 0.5 \\
\hline & 7 & 0.53 & - & - & 0.54 & - & - \\
\hline Ortalama & & & 0.5 & & & 0.5 & \\
\hline$\sigma_{\mathrm{c} \text { (kütle) }}$ & 16 & - & 0.97 & - & - & 2.25 & - \\
\hline \multirow[t]{11}{*}{ (MPa) } & 17 & 0.26 & 1.86 & 12.09 & 0.14 & 0.97 & 4.03 \\
\hline & 18 & 0.82 & 4.0 & 8.8 & 0.6 & 2.43 & 4.05 \\
\hline & $\begin{array}{l}20 \text { (denklem } \\
11,8 \text { 'den s) }\end{array}$ & 0 & 0.81 & 10.4 & 0 & 0.27 & 2.29 \\
\hline & $\begin{array}{l}20 \\
\text { (denk.11'den s) }\end{array}$ & - & 2.28 & - & - & 0.85 & - \\
\hline & 22 & - & 17.57 & - & - & 16.69 & - \\
\hline & 23 & 10.78 & 19.39 & 63.27 & 13.32 & 26.89 & 67.96 \\
\hline & 24 & 0.15 & 1.15 & 9.33 & 0.08 & 0.63 & 3.17 \\
\hline & 25 & 3.84 & 6.59 & 31.40 & 4.61 & 9.45 & 35.40 \\
\hline & 26 & 0.32 & 2.23 & 11.9 & 0.18 & 1.12 & 3.91 \\
\hline & 27 & - & 6.68 & - & - & 3.61 & - \\
\hline & 28 & - & 7.34 & - & - & 5.17 & - \\
\hline Ortalama & & & 5.07 & & & 4.32 & \\
\hline $\mathrm{E}_{\text {(kütle) }}$ & 29 & - & - & 38 & - & - & 42 \\
\hline \multirow[t]{10}{*}{$(\mathrm{GPa})$} & 30 & 3.98 & 6.68 & - & 4.73 & 9.44 & - \\
\hline & 31 & 2.32 & 8.01 & 10.29 & 0.91 & 2.73 & 3.74 \\
\hline & 33 & 1.68 & 2.91 & 14.03 & 2.01 & 4.18 & 15.84 \\
\hline & 34 & - & 2.84 & - & - & 1.03 & - \\
\hline & 35 & 1.67 & 6.43 & 12.75 & 0.68 & 2.38 & 4.87 \\
\hline & 36 & 2.56 & 5.88 & 31.35 & 3.45 & 9.33 & 34.69 \\
\hline & 37 & 0.42 & 2.82 & 26.41 & 0.28 & 1.51 & 10.36 \\
\hline & 38 & 3.93 & 7.95 & 32.85 & 5.06 & 11.76 & 35.79 \\
\hline & 40 & - & 6.38 & - & - & 4.48 & - \\
\hline & 41 & 0.13 & 1.64 & 12.09 & 0.05 & 0.48 & 3.96 \\
\hline Ortalama & & & 5.15 & & & 4.73 & \\
\hline
\end{tabular}




\subsection{Kaya kütlesine ait dayanımı}

[25] kaya kütle dayanımını hesaplamak için bir denklem önermiştir ve bu denklemdeki $\sigma_{\mathrm{ci}}$ bozulmamış kayanın MPa cinsinden UCS değeridir.

$\sigma_{\mathrm{c}(\text { kütle })}=\sigma_{\mathrm{ci}} \cdot \exp [7.65 .(\mathrm{RMR}-100) / 18.75] \quad(\mathrm{MPa})$

[26] $\sigma_{\mathrm{c}(k \mathrm{ütl}) \text { ' }} \mathrm{yi}$ hesaplamak için bir denklem önermiştir. Burada B metre cinsinden tünel genişliği, $\gamma$ ise $\mathrm{t} / \mathrm{m}^{3}$ cinsinden kaya kütlesinin birim hacim ağırlığıdır.

$\sigma_{\mathrm{c}(\text { kütle })}=\left[5.5 \cdot \gamma \cdot\left(\mathrm{Q}_{\mathrm{N}}\right)^{1 / 3}\right] /\left[\sigma_{\mathrm{ci}} \cdot(\mathrm{B})^{0.1}\right]$

(MPa)

[27] kayaçların $\sigma_{\mathrm{c}(\text { kütle })}$ 'sini hesaplamak için aşağıdaki denklemi önermiştir;

$\sigma_{\mathrm{c}(\text { kütle })}=\sigma_{\mathrm{ci}} \cdot \exp [(\mathrm{RMR}-100) / 24]$

(MPa)

[12] kayaçların $\sigma_{\mathrm{c}(k u ̈ t l e)}$ 'sini hesaplamak için aşağıdaki denklemi önermiştir;

$\sigma_{\mathrm{c}(\mathrm{kütle})}=\sigma_{\mathrm{ci}} \cdot \mathrm{Jp}$

(MPa)

[20] aşağıdaki gibi genelleştirilmiş ampirik yenilme kriteri önermiştir;

$\sigma_{1}^{\prime}=\sigma_{3}^{\prime}+\sigma_{\mathrm{ci}} \cdot\left[\mathrm{m}_{\mathrm{b}} \cdot\left(\sigma_{3}^{\prime} / \sigma_{\mathrm{ci}}\right)+\mathrm{s}\right]^{\mathrm{a}}$

Burada $\sigma_{1}^{\prime}$ etkili en büyük asal gerilme, $\sigma_{3}^{\prime}$ ise etkili en küçük asal gerilmedir. Kaya kütlesinin UCS'sini belirlerken, $\sigma_{3}^{\prime} 0$ olarak kabul edilir ve $\sigma_{\mathrm{ci}}$ ise laboratuvar testlerden elde edilir. Böylece, Denklem 12 Denklem 13 haline dönüştürülerek $\sigma_{1}^{\prime}$ hesaplanır. Bu değer $\sigma_{\mathrm{c}(\text { kütle) }}$ adını alarak aynı zamanda kaya kütlesinin UCS'si haline gelir.

$\sigma_{\mathrm{c}(\text { kütle })}=\sigma_{\mathrm{ci}} \cdot \mathrm{s}^{\mathrm{a}}$

[28] Q>10 olan sert kayaçlar için $\sigma_{c(k u ̈ u t l e)}$ 'yi hesaplamak için aşağıdaki denklemi önermiştir;

$\sigma_{\mathrm{c}(\text { kütle) }}=\left(\sigma_{\mathrm{ci}} / 100\right) \cdot 7 \cdot \gamma \cdot(\mathrm{Q})^{1 / 3}$

(MPa)

[22] $\mathrm{Q}<10$ ve $\sigma_{\mathrm{ci}}>2$ olan kayaçlar için Denklem 21'i aşağıdaki gibi değiştirilmiştir.

$\sigma_{\mathrm{c}(\text { kütle })}=7 \cdot \gamma \cdot(\mathrm{Q})^{1 / 3}$

(MPa)

[29] kayaçların $\sigma_{\mathrm{c}(k u ̈ t l e)}$ 'sini hesaplamak için aşağıdaki denklemi önermiştir;

$\sigma_{\mathrm{c}(\text { kütle })}=0,0016 .(\mathrm{RMR})^{2.5}$

(MPa)

[30] kayaçların $\sigma_{\mathrm{c}(k u ̈ t l e)}$ 'sini hesaplamak için aşağıdaki denklemi önermiştir; 
Türkiye’nin En Uzun Sulama Tüneli Suruç Tünelinde Geoteknik ve Tahkimat Tasarımlar

$\sigma_{\mathrm{c}(\text { kütle })}=\sigma_{\mathrm{ci}} \cdot \exp [(\mathrm{RMR}-100) / 20] \quad$ MPa $)$

[31] kaya kütlelerinin RMR değerlerini kullanarak $\left.\sigma_{c(k u ̈ t t e)}\right) \operatorname{sini}$ hesaplamak için aşağıdaki denklemi önermiştir;

$\sigma_{\mathrm{c}(\text { kütle) }}=0.5 . \exp (0.06 . \mathrm{RMR})$

(MPa)

[32] kayaçların $\sigma_{\mathrm{c}(k u ̈ t l e)}$ 'sini hesaplamak için aşağıdaki denklemi önermiştir;

$\sigma_{\mathrm{c}(\text { kütle })}=\sigma_{\mathrm{ci}} \cdot[\mathrm{RMR} /(\mathrm{RMR}+6 .(100-\mathrm{RMR})] \quad(\mathrm{MPa})$

[33] kaya kütlelerinin $Q$ değerlerini kullanarak $\left.\sigma_{\mathrm{c}(k u ̈ t l e)}\right) \operatorname{sini}$ hesaplamak için aşağıdaki denklemi önermiştir;

$\sigma_{\mathrm{c}(\text { kütle })}=5 \cdot \gamma \cdot\left[\mathrm{Q} \cdot\left(\sigma_{\mathrm{ci}} / 100\right)\right]^{1 / 2}$

[21] kaya kütlelerinin $\mathrm{Q}_{\mathrm{C}}$ değerlerini kullanarak $\sigma_{\mathrm{c}(\mathrm{kütl})}$ 'sini hesaplamak için aşağıdaki denklemi önermiştir;

$\sigma_{\mathrm{c}(\text { kütle })}=5 \cdot \gamma \cdot(\mathrm{Qc})^{1 / 3}$

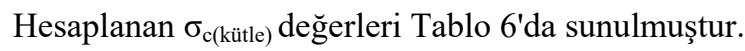

\subsection{Kaya kütlesinin deformasyon modülü}

Kaya kütlelerinin yerinde deformasyon modülü olan $\mathrm{E}_{\text {kütle }}$ 'yi RMR, Q, GSI ve UCS değerleri kullanarak dolaylı olarak tahmin edebilecek bazı önermeler literatürde bulunmaktadır.

[34] RMR $>50$ olan kaya kütlesinin RMR değerleri kullanılarak $\mathrm{E}_{(\text {kütle })}$ hesaplamak için aşağıdaki denklemi önermiştir;

$\mathrm{E}_{(\text {kütle })}=2 \cdot$ RMR -100

$(\mathrm{GPa})$

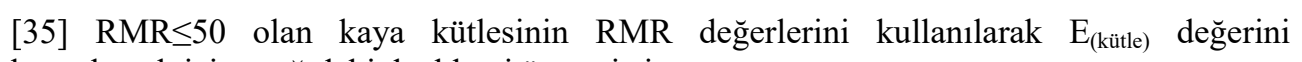
hesaplamak için aşağıdaki denklemi önermiştir;

$\mathrm{E}_{(\text {kütle) }}=10^{(\mathrm{RMR}-10) / 40}$

[36] kaya kütlesinin $E_{i}$ ve $R F$ değerlerini kullanılarak $E_{(\text {(kütle) }}$ değerini hesaplamak için aşağıdaki denklemi önermiştir;

$\mathrm{E}_{(\text {kütle) }}=\mathrm{E}_{\mathrm{i}} \cdot \mathrm{RF}$

$E_{i}$ bozulmamış kaya elastik modülü ve RF ise [36] tarafından ifade edilen yüzde olarak azalma faktörüdür; 
$\mathrm{RF}=0.0028 . \mathrm{RMR}^{2}+0.9 \cdot \exp (\mathrm{RMR} / 22.82)$

[37] zayıf kayaçlardaki 50 m'den derin tüneller için $\mathrm{E}_{(\text {kütle }}$ değerini hesaplamak için aşağıdaki denklemi önermiştir;

$\mathrm{E}_{(\mathrm{kütle})}=0.3 \cdot \mathrm{H}^{\alpha} \cdot 10^{(\mathrm{RMR}-20) / 38} \quad(\mathrm{GPa})$

Burada H tünel derinliğidir, $\alpha$ ise çok zayıf kayalar için 0,30 - çok sert kayalar için 0.16 arasında değişen bir faktördür. Bu çalışmada, $\mathrm{H} 80 \mathrm{~m}, \alpha$ ise 0.2 olarak seçilmiştir.

[15] Q>1 olan kaya kütlesinin $\mathrm{E}_{(\text {kütle) }}$ 'sini hesaplamak için aşağıdaki denklemi önermiştir;

$\mathrm{E}_{(\text {kütle) }}=25 . \log \mathrm{Q}$

(GPa)

[38] kayaçların $\mathrm{E}_{(\text {kütle) }}$ 'sini hesaplamak için aşağıdaki denklemi önermiştir;

$\mathrm{E}_{(\mathrm{kütle})}=\mathrm{E}_{\mathrm{i}} \cdot 0.5 \cdot[1-\operatorname{Cos} \pi(\mathrm{RMR} / 100)]$

$(\mathrm{GPa})$

[29] kayaçların $E_{(\text {kütle) }}$ 'sini hesaplamak için aşağıdaki gibi bir denklem önermiştir;

$\mathrm{E}_{(\mathrm{kütle})}=0.0097 .(\mathrm{RMR})^{3.54}$

(MPa)

[39] $\sigma_{\mathrm{ci}}<100 \mathrm{MPa}$ olan zayıf kayaçların GSI değerini kullanarak $\mathrm{E}_{(\mathrm{kütle})}$ 'sini hesaplamak için aşağıdaki denklemi önermiştir;

$\mathrm{E}_{(\mathrm{kütle})}=\left(\sigma_{\mathrm{ci}} / 100\right)^{0.5} \cdot 10^{(\mathrm{GSI}-10) / 40}$

$(\mathrm{GPa})$

[40] kayaçların RMR değerini kullanarak $\mathrm{E}_{(\text {(kütle) }}$ 'sini hesaplamak için aşağıdaki denklemi önermiştir;

$\mathrm{E}_{(\text {kütle })}=0.1 .(\mathrm{RMR} / 10)^{3}$

$(\mathrm{GPa})$

[12] $\mathrm{RMI}>0.1$ olan kayaçların $\mathrm{E}_{(\text {kütle }}$ ') $\operatorname{sini}$ hesaplamak için aşağıdaki denklemi önermiştir;

$\mathrm{E}_{(\mathrm{kütle})}=5.6 \cdot(\mathrm{RMI})^{0.375}$

$(\mathrm{GPa})$

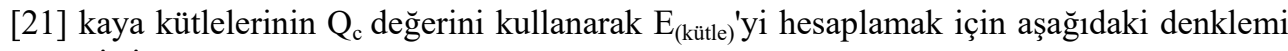
önermiştir;

$\mathrm{E}_{(\mathrm{kütle})}=10 \cdot(\mathrm{Qc})^{1 / 3}$

$(\mathrm{GPa})$

Son olarak [41] kayaçların $\mathrm{E}_{\mathrm{i}}$ ve D değerini kullanarak $\mathrm{E}_{(\mathrm{kütle})}$ 'sini hesaplamak için aşağıdaki denklemi önermiştir;

$\mathrm{E}_{(\mathrm{kütle})}=\mathrm{E}_{\mathrm{i}} \cdot\{0.02+[1-(\mathrm{D} / 2)] /[1+\exp ((60+15 . \mathrm{D}-\mathrm{GSI}) / 11)]\}(\mathrm{GPa})$ 
Türkiye’nin En Uzun Sulama Tüneli Suruç Tünelinde Geoteknik ve Tahkimat Tasarımlar

Tünel güzergâhından elde edilen kaya kütlesi sabitleri $\mathrm{m}_{\mathrm{i}}, \mathrm{m}_{\mathrm{b}}$, $\mathrm{s}$ ve a, kaya kütlesi dayanımı $\sigma_{\mathrm{c} \text { (kütle) }}$ ve kaya kütlelerinin yerinde deformasyon modülü $\mathrm{E}_{(\text {kütle }}$ değerleri Tablo 6'da topluca sunulmuştur.

\section{TAHKIMMAT BASINCININ BELIRLENMESİ VE TAHKIMAT TASARIMI}

Bu çalışmada tahkimat basınçlarının $\left(\mathrm{P}_{\mathrm{i}}\right)$ tahmininde $\mathrm{Q}$ ve RMR kaya kütlesi sınıflandırma sistemleri kullanılmıştır. Ancak, kaya kütlesi sınıflandırma sistemleri her ne kadar destek basıncı ve destek ihtiyaçlarının belirlenmesinde başarılı olsa da, tüneli çevreleyen kaya kütlesiyle destekler arasındaki etkileşimleri yok sayarlar. Bu zaafı ortadan kaldırmak ve emniyetli tünel destek tasarımı yapabilmek amacıyla, aynı hesaplamalar analitik ve sayısal yöntemler de tekrarlanarak, ampirik yöntemlerle elde edilen sonuçlar kontrol edilmiştir.

\subsection{Tahkimat basıncının tahmini}

[11] kaya kütlesinin $\mathrm{Q}$ değerleri kullanarak destek basıncını $\left(\mathrm{P}_{\mathrm{i}}\right)$ hesaplamak için aşağıdaki denklemi önermiştir;

$\mathrm{P}_{\mathrm{i}}=0.2 \cdot \mathrm{Q}^{-1 / 3} / \mathrm{Jr}$

[42] kaya kütlesinin RMR, $\gamma$ ve B değerlerini kullanarak Pi hesaplamak için aşağıdaki denklemi önermiştir;

$P_{i}=[(100-R M R) / 100] \cdot \gamma \cdot B$

[19] 50 m 'den derin tüneldeki kaya kütlesinin RMR, B ve H değerlerini kullanarak Pi hesaplamak için aşağıdaki denklemi önermiştir;

$\mathrm{P}_{\mathrm{i}}=\left(7.5 \cdot \mathrm{B}^{0.1} \cdot \mathrm{H}^{0.5}-\mathrm{RMR}\right) / 20 \cdot \mathrm{RMR}$

Tünel güzergahındaki kireçtaşı ve marn jeolojik birimlerinin destek basınç miktarları hesaplanmış ve Tablo 7'de sunulmuştur.

Tablo 7. Suruç tüneli için destek basıncı hesapları (MPa)

\begin{tabular}{cccc} 
Denklem no & Kireçtaş1 & Marn & Fay zonu \\
\hline 42 & 0.06 & 0.07 & 2.31 \\
44 & 0.05 & 0.09 & 0.22
\end{tabular}

\subsection{Ampirik Yöntemler}

Ampirik yöntemler olan RMR ve Q sistemleri kullanılarak tünel için gerekli destek sistemleri seçilmiştir. Kireçtaşı ve marn için ortalama RMR değerleri sırasıyla, 43 ve 49'dur. Her iki birimde III sınıf kaya kütlesi sınıfındadır. III. sınıf kaya kütlesi için RMR 
sistemi $4 \mathrm{~m}$ uzunluğunda sistematik kaya saplaması, duvarlarda ve taç kısmında 1,5-2 m aralıklı tel hasır, tavanda $50-100 \mathrm{~mm}$ duvarda ise $30 \mathrm{~mm}$ kalınlığında püskürtme beton önermektedir.

[11] tarafından önerilen eşdeğer boyut $\left(D_{e}\right)$ kazı destek oranı (KDO) ve kazı açıklı̆̆ parametreleriyle aşağıdaki gibi ifade edilebilir.

$D_{e}=$ Kazı açıklı̆̆ı, çap veya yükseklik ( m ) / Kazı Destek oranı, KDO

Suruç tünelinin kazı açıklığı $7 \mathrm{~m}$ ve KDO 1,6 olarak kabul edilmiş, $\mathrm{D}_{\mathrm{e}} 4.37$ olarak hesaplanmıştır.

[11] ve [15] $D_{e}$ ve $Q$ değerlerine göre bazı destek grafikleri önermektedir. Bunlarda kireçtaşı birimi için $\mathrm{D}_{\mathrm{e}}$ değeri 4.37 ve $\mathrm{Q}$ değeri de 1.3 olduğundan, $1.8 \mathrm{~m}$ aralı̆̆ında ve 3.7 $\mathrm{m}$ uzunluğunda kaya bulonunun ve $4.5 \mathrm{~cm}$ kalınlıkta çelik lif takviyeli püskürtme betonu önerilmiştir. Marn için $\mathrm{D}_{\mathrm{e}}$ değeri 4.37 ve $\mathrm{Q}$ değeri de 1.1 olduğundan, $1.7 \mathrm{~m}$ aralığında ve $3.7 \mathrm{~m}$ uzunluğunda kaya bulonları ve $5 \mathrm{~cm}$ kalınlıkta çelik lif takviyeli püskürtme betonu önerilmiştir.

\section{3. Çözümlemeli yöntem}

Destek ihtiyacı çözümlemeli olarak convergence-confinement yöntemi ile belirlenmiştir. $\mathrm{Bu}$ yöntem ilk olarak [43] tarafindan önerilmiştir. Bu yöntemde zeminin ve uygulanacak desteğin deformasyon özelliklerine ihtiyacı vardır. Böylece, destek üzerine tahmini yükler uygulanabilmektedir. Convergence-confinement yöntemi Hoek-Brown yenilme kriterini karşılayan kaya kütleleri için uygun olup, ilk olarak [44-47] tarafindan uygulanmıştır.

Tünel yarıçapı $\mathrm{R}$, yarıçapa bağlı düzgün gerilme alanı $\mathrm{S}_{0}$ ve tünel iç basıncı $\mathrm{p}_{\mathrm{i}}$ olarak kabul edilirse, kritik destek basıncı $p_{i}^{c r}$ aşağıdaki gibi ifade edilir;

$p_{i}^{c r}=\left[\mathrm{P}_{\mathrm{i}}^{\mathrm{cr}}-\left(\mathrm{s} / \mathrm{m}_{\mathrm{b}}^{2}\right)\right] \cdot \mathrm{m}_{\mathrm{b}} \cdot \sigma_{\mathrm{ci}}$

Burada $P_{i}^{\text {cr }}$ aşağıdaki formül ile elde edilebilen ölçekli kritik basınçtır.

$\mathrm{P}_{\mathrm{i}}^{\mathrm{cr}}=0.0625 \cdot\left[1-\left(1+16 \cdot \mathrm{S}_{0}\right)^{0.5}\right]^{2}$

$\mathrm{S}_{0}$ aşağıdaki formül ile verilen ölçekli gerilme alanıdır.

$\mathrm{S}_{0}=\left(\sigma_{0} / \mathrm{m}_{\mathrm{b}} \cdot \sigma_{\mathrm{ci}}\right)+\left(\mathrm{s} / \mathrm{m}_{\mathrm{b}}{ }^{2}\right)$

Eğer $p i>p i^{c r}$ ise yenilme beklenmez. Bu durumda, kaya kütlesinin çevresi elastik davranış gösterir. Aşağıdaki denklem ise, tünel duvarlarındaki içe doğru elastik yer değiştirmeyi verir. Kaya kütlesinin kayma modülüne $\mathrm{G}_{\mathrm{rm}}$ denir.

$\mathrm{u}_{\mathrm{r}}^{\mathrm{el}}=\mathrm{R} \cdot\left(\sigma_{0}-p_{i}\right) /\left(2 \cdot \mathrm{G}_{\mathrm{rm}}\right) \quad(\mathrm{mm})$

Eğer $p_{i} p_{i}^{c r}$ den düşük ise yenilme beklenir. Kırık bölgenin yarıçapı $\mathrm{R}_{\mathrm{pl}}$ aşağıdaki gibi tanımlanır; 
Türkiye’nin En Uzun Sulama Tüneli Suruç Tünelinde Geoteknik ve Tahkimat Tasarımlar

$\mathrm{R}_{\mathrm{pl}}=\mathrm{R} \cdot \exp \left[2 \cdot\left(\mathrm{P}_{\mathrm{i}}^{\mathrm{cr}}-\left(\mathrm{P}_{\mathrm{i}}\right)^{0.5}\right)^{0.5}\right]$

[13] bazı durumlarda plastik hacmin değiş̧mediğini varsaymanın daha uygun olabileceğini belirtmiştir. Bu durumda, toplam içe doğru plastik deformasyon aşağıdaki gibi hesaplanır;

$\mathrm{u}_{\mathrm{r}}^{\mathrm{pl}}=\left[\left(\sigma_{0}-p_{i}^{\mathrm{cr}}\right) /\left(2 \cdot \mathrm{R} \cdot \mathrm{G}_{\mathrm{rm}}\right)\right] \cdot\left\{[(1-2 \cdot v) / 2] \cdot\left[\left(\mathrm{P}_{\mathrm{i}}^{\mathrm{cr}}\right)^{0.5} /\left(\mathrm{S}_{0}-\mathrm{P}_{\mathrm{i}}^{\mathrm{cr}}\right)\right]+1\right\} \cdot\left(\mathrm{R}_{\mathrm{pl}} / \mathrm{R}\right)$

$+\left\{(1-2 . v) /\left[4 \cdot\left(\mathrm{S}_{0}-\mathrm{P}_{\mathrm{i}}^{\mathrm{cr}}\right)\right]\right\} \cdot\left[\ln \left(\mathrm{R}_{\mathrm{pl}} / \mathrm{R}\right)\right]^{2}-[(1-2 \cdot v) / 2] \cdot\left[\left(\mathrm{P}_{\mathrm{i}}^{\mathrm{cr}}\right)^{0.5} /\left(\mathrm{S}_{0}-\mathrm{P}_{\mathrm{i}}^{\mathrm{cr}}\right)\right]$

.[2. $\left.\ln \left(\mathrm{R}_{\mathrm{p} 1} / \mathrm{R}\right)+1\right]$

$(\mathrm{mm})$

Burada v Poisson oranıdır. Bu çalışmada parametrelerin hesaplanması için [45]'in önerileri izlenmiştir. Suruç tünel için $\mathrm{R}$ ve $\sigma_{0}$ değerleri kireçtaşı ve marnda benzerdir ve bunlar sırasıyla $7 \mathrm{~m}$ ve $1.84 \mathrm{MPa}$ olarak alınmıştır. İç destek basıncı $p_{i}$, tünelin desteklenmeyen kısımları için sıfır kabul edilmiştir. Kritik destek basıncı, desteklenmeyen tünel için en fazla deformasyonlar, plastik bölgelerin yarıçapı ve gerilme değerleri Tablo 8'de sunulmuştur.

Tablo 8. Kritik destek basıncl, plastik bölge, en fazla deformasyon ve yüzdeleri

\begin{tabular}{ccccc} 
Birim & $\begin{array}{c}\text { Kritik destek } \\
\text { basınc1 } \\
p_{\mathrm{cr}}, \mathrm{MPa}\end{array}$ & $\begin{array}{c}\text { Plastik zon } \\
\text { bölgesi } \\
\mathrm{R}_{\mathrm{pl}}, \mathrm{m}\end{array}$ & $\begin{array}{c}\text { En fazla } \\
\text { deformasyon } \\
\mathrm{u}_{\max }, \mathrm{mm}\end{array}$ & $\begin{array}{c}\text { Deformasyon, } \\
\%\end{array}$ \\
\hline Kireçtaş1 & 0.023 & 4.7 & 18.7 & 0.27 \\
Marn & 0.009 & 4.0 & 16.4 & 0.24
\end{tabular}

[48] gerilmeler, geoteknik sorunlar ve destek türleri arasındaki bazı ilişkileri için Tablo 9'u önermiştir.

Tablo 8 ve 9'dan görüldüğü gibi, kireçtaşı ve marn birimlerinin her ikisinin de gerilme değerleri \%1'den azdır. Kaya kütlesi sınıflama sistemleri tarafından tavsiye edilen destek sistemleri Tablo 10'da sunulmaktadır.

Tablo 9. Deformasyon geoteknik problemler ve destek tipleri arasindaki ilişki [48]

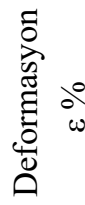

Geoteknik problemler Destek tipi

Çok basit tünel destekleri. Çok iyi tünel koşulları, az yoğunlukta Bazı duraylılık sorunları tavan saplamaları ve püskürtme beton.

A $<1$ olabilir. Kaya kütlesi sınıflama sistemi tasarım için uygun bir dayanak oluşturur. 


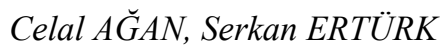

Tablo 9. Deformasyon geoteknik problemler ve destek tipleri arasindaki ilişki [48] (devam)

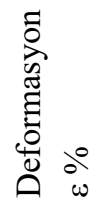
Geoteknik problemler
Destek tipi
Convergence-confinement
Tavan saplamaları ve püskürtme beton yöntemi bölgenin aşamalı gelişiminin, farklı destek kaplama. Bazı durumlarda çelik bağlar
B $1-2.5$ türleri arasındaki etkileşimin gerekebilir. ve tüneldeki kaya kütlesini çevreleyen plastik zonun oluşumunu öngörmek için kullanilır.
Sıkışmanın düzeyi daha 'alın duraylılı̆̆ı' önemli bir sorun oluşturmaz.
C $\quad 2.5-5$ belirgindir. Genellikle kazı
İksanın hızlı bir şekilde yerleştirilmesi gerekmektedir. Püskürtme beton kaplaması içinde ağır profilli çelik desteklerin yerleştirilmesi gerebilir.

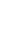
Tünel tasarımında iki boyutlu
D 5- 10 sonlu analizler kullanılır. Alın duraylilik problemleri yoğunlaşmaktadır.
Şiddetli alın duraylılık sorunuyla beraber sıkışma
E $>10$ olmaktadır.
Çok ciddi sıkışma ve alın duraylılık sorunları olmaktadır. Hızlı bir şekilde püskürtme beton ile birlikte çelik destek yerleştirilmesi gerekmektedir.
Aşırı sıkışma nedeniyle tavanda süren ve alında güçlendirme gerekmektedir. Sıkışmanın denetimi açısından püskürtme beton kaplaması içinde esnek çelik bağ kullanımı tercih edilebilir.

Tablo 10. Kaya kütlesi sinıflama sistemi tarafindan önerilen Suruç tünelinin destek sistemi

\begin{tabular}{|c|c|c|c|c|}
\hline Yöntem & Birim & Kireçtaş1 & Marn & Fay \\
\hline \multirow[t]{3}{*}{ Q } & Q & 1.3 & 1.1 & 0.0052 \\
\hline & Span/ESR & 4.37 & 4.37 & 4.37 \\
\hline & Destek & $\begin{array}{l}2 \mathrm{~m} \text { uzunluğunda } \\
\text { sistematik } \\
\text { bulon, } 1.8 \mathrm{~m} \\
\text { aralıklı, } 4.5 \mathrm{~cm} \\
\text { liflerle } \\
\text { güçlendirilmiş } \\
\text { püskürtme beton }\end{array}$ & $\begin{array}{l}2 \mathrm{~m} \text { uzunluğunda } \\
\text { sistematik bulon, } \\
1.7 \mathrm{~m} \text { aralıklı, } \\
\mathrm{cm} \text { liflerle } \\
\text { güçlendirilmiş } \\
\text { püskürtme beton }\end{array}$ & $\begin{array}{l}2 \mathrm{~m} \text { uzunluğunda } \\
\text { sistematik bulon, } 0.8 \\
\text { m aralıklı, } 20 \mathrm{~cm} \\
\text { liflerle güçlendirilmiş } \\
\text { püskürtme beton }\end{array}$ \\
\hline
\end{tabular}


Türkiye’nin En Uzun Sulama Tüneli Suruç Tünelinde Geoteknik ve Tahkimat Tasarımlar

Tablo 10. Kaya kütlesi slnıflama sistemi tarafindan önerilen Suruç tünelinin destek sistemi (devam)

\begin{tabular}{|c|c|c|c|c|}
\hline Yöntem & Birim & Kireçtaş1 & Marn & Fay \\
\hline RMR & $\begin{array}{l}\text { RMR } \\
\text { Destek }\end{array}$ & $\begin{array}{l}43 \\
4 \mathrm{~m} \text { uzunluğunda } \\
\text { sistematik } \\
\text { bulon, taç } \\
\text { kısmında tel } \\
\text { kafes ile duvar } \\
\text { ve taç } \\
\text { kisımlarında } \\
1.5-2 \mathrm{~m} \text { aralıklı. } \\
\text { Püskürtme } \\
\text { beton taç } \\
\text { kısmında 5-10 } \\
\mathrm{cm} \text {, kenarlarda } 3 \\
\mathrm{~cm}\end{array}$ & $\begin{array}{l}49 \\
4 \mathrm{~m} \text { uzunluğunda } \\
\text { sistematik bulon, } \\
\text { taç kısmında tel } \\
\text { kafes ile } 1.5-2 \mathrm{~m} \\
\text { aralıkl. } \\
\text { Püskürtme beton } \\
\text { taç kismında 5-10 } \\
\mathrm{cm} \text {, kenarlarda } 3 \\
\mathrm{~cm}\end{array}$ & $\begin{array}{l}15 \\
5-6 \mathrm{~m} \text { uzunluğunda } \\
\text { sistematik bulon, tel } \\
\text { kafes ile duvar ve taç } \\
\text { kısmında } 1-1.5 \mathrm{~m} \\
\text { aralılıl. invert } \\
\text { saplaması. püskürtme } \\
\text { beton taç kısmında } \\
15-20 \mathrm{~cm} \text {, kenarda } 15 \\
\mathrm{~cm} \text {, ve yüzeyde } 5 \mathrm{~cm} \text {. } \\
\text { ortalama ağırlıktaki } \\
\text { nervür mesafesi } 0.75 \\
\text { m çelik kaplama ve } \\
\text { destek kesit } \\
\text { kapatılıalı } \\
\text { gereklidir. }\end{array}$ \\
\hline
\end{tabular}

\subsection{Sayısal yöntem}

Gerilmeleri, deformasyonları ve destek basınçlarını modellemek amacıyla Plaxis 8.2 yazılımı kullanılmıştır. Bu yazılım iki-boyutlu sonlu elemanlar yöntemiyle çözüm yapabilmektedir [3]. Sonlu elemanlar analizine kaya kütlesi davranışlarını daha iyi yansıtabilmek amacıyla Hoek-Brown yenilme kriteri kullanılmıştır. Hoek-Brown yenilme kriteriyle uyumlu olabilmek için, lineer-elastik malzeme modeli seçilmiştir. Lineer-elastik malzeme modeline uyumlu olduğu için [3], malzeme tipi olarak gözeneksiz davranış seçilmiştir. Girdi parametreleri birim ağırlık, Young modülü, Poisson oranı ve içsel sürtünme açısıdır.

Modelin dış sınırı tünel çapının 2 katı olarak tasarlanmıştır. Tünel çapı $7 \mathrm{~m}$ olarak girilmiştir. Kireçtaşı ve marn için yüzeyin altında tünel kazı derinliği sırasıyla $80 \mathrm{~m}$ ve 50 m olarak varsayılmıştır. Kaya kütlesinin giriş parametreleri için Bölüm 4'te verilen değerler seçilmiştir. Emniyetli tarafta kalabilmek için mekanik parametrelerin artık değerlerinin pik değerlerin yarısı kadar oldukları varsayılmıştır. Düşey gerilmelerin örtü kalınlığının bir fonksiyonu olduğu varsayılmıştır. Yeraltı suyu yüzeyden $20 \mathrm{~m}$ derinde olarak girilmiştir. Böylece, Plaxis 8.2 yazılımı analizlerine göre yerinde düşey gerilmeler $1.1 \mathrm{MPa}$, yatay gerilmeler 1.6 MPa hidrostatik basınç ise $0.68 \mathrm{MPa}$ olarak belirlenmiştir. Bu sonuçlar [29]'un önerileriyle uyumlu bulunmuştur.

Analiz üç aşamada gerçekleştirilmiştir. Birinci analizde desteksiz kazı koşulları, ikinci analizde Q sistemiyle destekli ve üçüncü analizde ise tam kesit TBM kazı sistemiyle beton kaplama destek sistemleri incelenmiştir. RMR sisteminde gerilme, eklem pürüzlülüğü ve eklem dolgusu gibi parametreler dikkate alınmadığı için, Q sistemi destek önerilerinin incelenmesi uygun görülmüştür. Otomatik ağ oluşturma seçeneği kullanılmış olup, tünel 
çevresi daha sık ağlarla modellenmiştir. Daha sonra tünel çevresinde oluşan gerilmeler ve deformasyonlar hesaplanmıştır. Kireçtaşı ve marn birimleri için hesaplanan gerilmeler, deformasyonlar ve plastik noktalar Şekil 7 ve Şekil 8'de sunulmuştur.

Desteklenmiş ve desteklenmemiş durumlar için plastik bölgenin ölçütü, tünelin deformasyonları ve gerilmeleri incelemiştir. Tablo 11'de görüldüğü gibi deformasyonlar çok küçük olmasına rağmen $(1.47 \mathrm{~mm})$, kireçtaşı ve marn birimlerinden gecen fay zonları ve tünelin desteklenmeyen kısımlarında bazı duraysızlıklar olacağı anlamına gelmektedir.

Deformasyonlar ve plastik bölgenin büyüklüğü TBM sistemindeki beton destek kaplamaları ve Q sisteminin destek elemanları tarafından en aza indirgenmiştir. Bunlar önerilen desteklerin yeterli olduğu anlamına gelmektedir. Şekil 7 ve Şekil 8'den görüldüğü gibi, kaya saplamaları aşırı gerilme altındaki zonu aşmaktadır. Ancak, fay zonlarında daha fazla destek elemanları gerekebilir. Fay zonunun bulunduğu yerde FEM için gerekli laboratuvar testleri gerçekleştirilemediğinden, fay zonları için sayısal analizler yapılamamıştır.

Analitik yöntemde belirlenen kalıcı deformasyona uğramış plastik bölgenin yarıçapı sayısal analizlerle belirlenenlerden daha büyüktür. Ancak, bazı sonlu elemanlar programlarının çok küçük gerilmelerde ve sayısal modelde sonlu ayrışmaların yol açtığı kü̧̈ük farklılaşmalara uygun olmayabilecekleri unutulmamalıdır. Bu yüzden [47]'nin belirttiği gibi, yenilmenin büyüklüğünden ziyade, plastik zonun yayılımının tespit edilmesi bu analizler açısından daha anlamlıdır.

Tablo 11. Plastik zonun yarıçapı, en büyük deformasyonlar ve destek basınçları

\begin{tabular}{llccc} 
& & Kireçtaşı & Marn \\
\hline Plastik zonun yarıçapı, $\mathrm{R}_{\mathrm{pl}}, \mathrm{m}$ & Desteksiz & 4.6 & 4.1 \\
& Q sistemi ile destekleme & 3.6 & 3.6 \\
& TBM kaplaması & ile & 3.6 & 3.6 \\
& destekleme & & & \\
En büyük deformasyon, $\mathrm{u}_{\text {kütle, }} \mathrm{mm}$ & $\begin{array}{l}\text { Desteksiz } \\
\end{array}$ & & 1.47 & 1.22 \\
& Q sistemi ile destekleme & 1.18 & 0.99 \\
& TBM kaplaması & ile & 1.15 & 0.90 \\
destekleme & & & \\
Destek basınc1, $\mathrm{MPa}$ & & & & \\
\hline
\end{tabular}


Türkiye'nin En Uzun Sulama Tüneli Suruç Tünelinde Geoteknik ve Tahkimat Tasarımlar

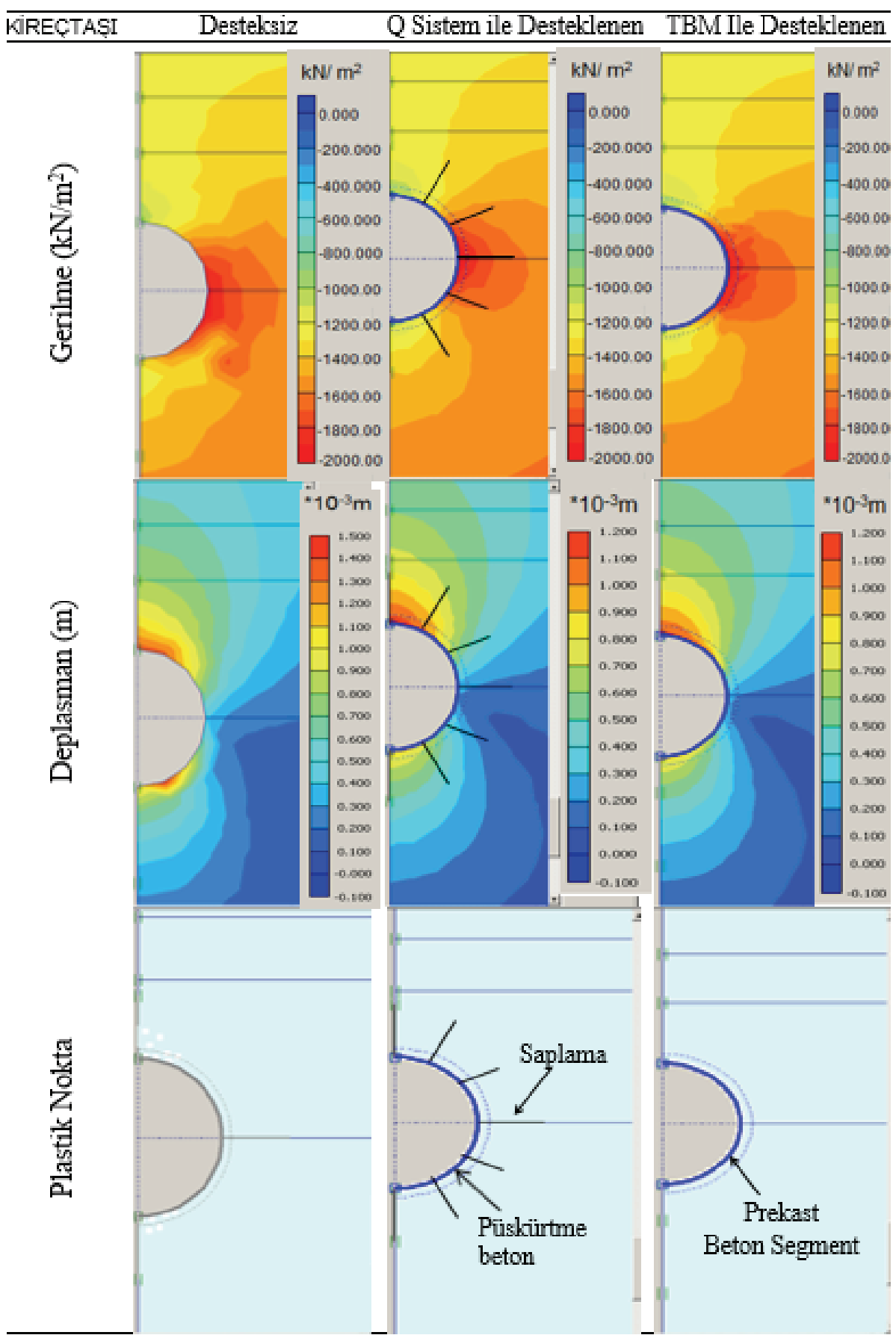

Şekil 7. Kireçtaşı bölgesindeki tünel için gerilmeler, yer değiştirmeler ve plastik noktalar 
Celal AĞAN, Serkan ERTÜRK

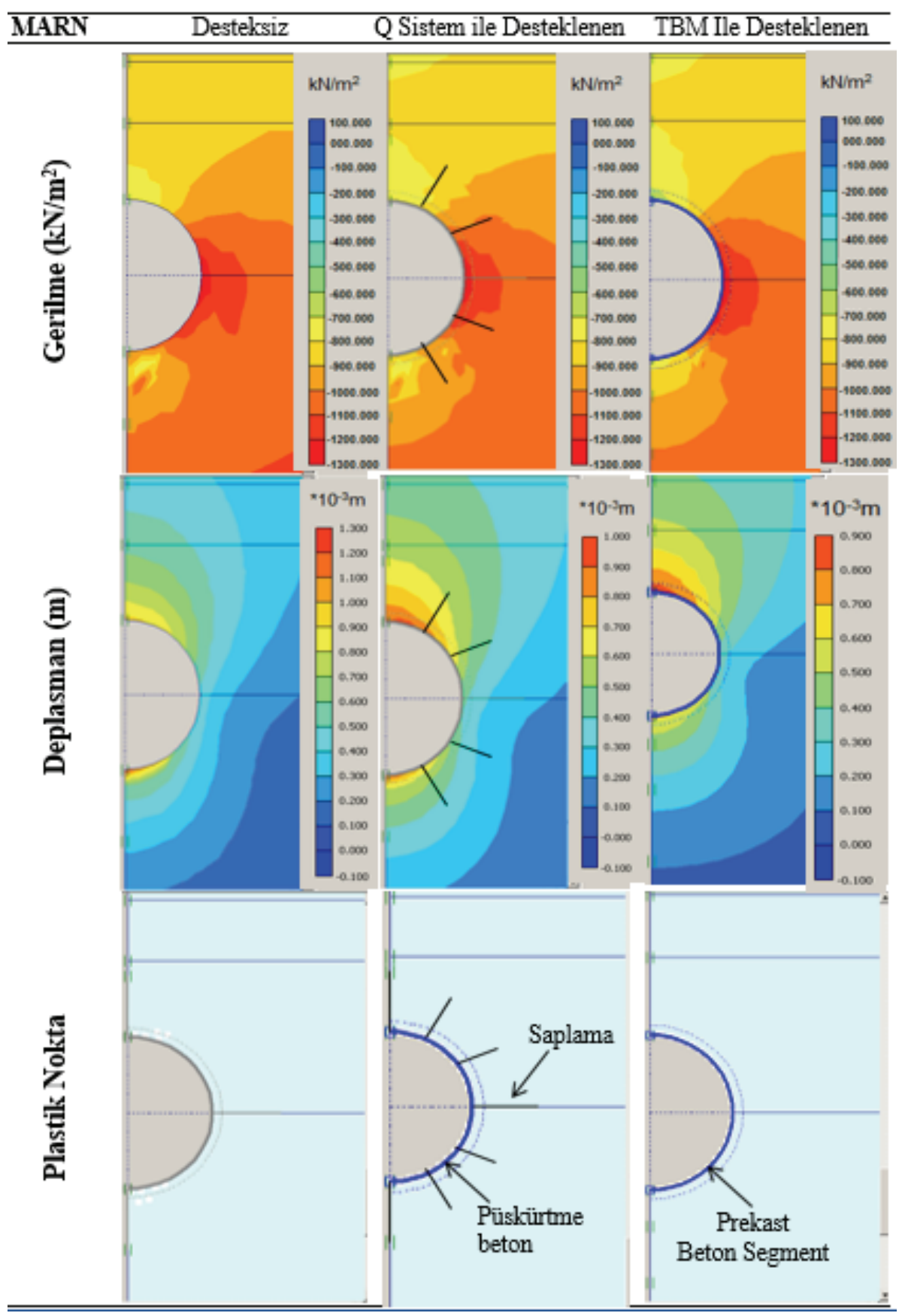

Sekil 8. Marn bölgesindeki tünel için gerilmeler, yer değiștirmeler ve plastik noktalar 


\section{YORUM VE ÖNERILER}

Ülkemizde her ne kadar karayolu tünelleriyle ilgili araştırmalar daha yaygın olsada [49], bu çalışmada Türkiye'nin birinci dünyanın beşinci en uzun sulama tüneli olan Suruç tüneline ait geoteknik araştırmalar, kaya kütlesi karakterizasyonu ve tahkimat tasarımları irdelenmiştir. Tünel kireçtaşı ve marn birimleri içerisinde kazılmaktadır. Kaya kütlelerinin karakterizasyonu RMR, Q ve GSI sistemleriyle, mekanik özellikleri ise laboratuvar testleriyle tespit edilmiştir. Süreksizliklerin niceliksel açıklamaları, doğrultuları ve eğimleri yerinde ölçümlerle tespit edilmiştir.

Bu çalışmanın sonuçlarına göre, kireçtaşı, marn ve fay zonu için bazı duraysızlık sorunları beklenmektedir. Çözümlemeli ve sayısal yöntemlerle, deformasyonlar ve tünelin desteksiz bölgelerindeki plastik alanlar belirlenmiştir. Ampirik yönteme göre, destek sistemleri olarak kaya saplaması ve püskürtme beton önerilmiştir. Ayrıca, Suruç tüneli tam kesit TBM ile kazılmakta olduğu için prekast beton kaplama da incelenmiştir. Analiz sonuçlarına göre, önerilen destek sistemleri sayesinde deformasyonlar ve plastik bölge sınırları azaltılmıştır. Deformasyonlardaki en fazla azalma beton kaplama destek sistemi ile elde edilmiştir.

$\mathrm{Bu}$ sonuçlara göre, bu çalışmada uygulanan ampirik, çözümlemeli ve sayısal analizler uyumlu sonuçlar vermiştir. Bundan dolayı, bu analizlerin tünel destek tasarımı projelerinde birlikte kullanılması önerilmektedir.

Bu çalışmanın en büyük noksanlığı, belirlenen deformasyonların tünelde yapılacak gerçek deformasyon ölçümleriyle teyit edilememesidir. Gerek kazı işleminin tam kesitli TBM ile yapılması gerekse de şantiye çalışmalarını aksatmamak adına gerçek deformasyon ölçümleri yapmak üzere tünelin çeşitli bölgelerinde teçhizatlandırma işlemi için çalışma izni alınamamıştır. Bundan sonraki çalışmalarda, ön tahminde bulunulmuş tünel deformasyon değerlerinin ve önerilen destek sistemlerinin doğruluğunun teyidi için, kazı çalışmaları sırasında ve sonrasında yerinde deformasyon ölçümlerinin yapılması önerilir.

\section{Semboller}

Kaya kütlesinin yüzey pürüzlülük katsayısı

ASTM American Society for Testing and Materials

CL Düşük plastisiteli kil

$\mathrm{C}_{\mathrm{L}} \quad$ Sol kazı kesiti

$\mathrm{C}_{\mathrm{R}} \quad$ Sağ kazı kesiti

ML Silt

D Hakim eklem seti

D Kazı metoduna bağlı olarak kaya kütlesi örselenme katsayısı

$\mathrm{D}_{\mathrm{e}} \quad$ Eşdeğer boyut

DSI Devlet Su İşleri

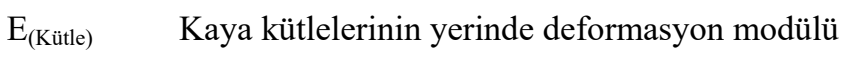

$\mathrm{E}_{\mathrm{I}} \quad$ Kaya numunesinin elastik modülü 


\begin{tabular}{|c|c|}
\hline$\varepsilon$ & Deformasyon (mm) \\
\hline GAP & Güneydoğu Anadolu Projesi \\
\hline GD & Güneydoğu \\
\hline GSI & Geological strength index (jeolojik dayanım indeksi) \\
\hline $\mathrm{G}_{\mathrm{rm}}$ & Kaya kütlesinin kayma modülü \\
\hline $\mathrm{H}$ & Örtü kalınlığı \\
\hline ha & Hektar \\
\hline $\mathrm{Jp}$ & Kaya kütlesinin eklemleme parametresi \\
\hline $\mathrm{Jn}$ & Çatlak seti sayısı \\
\hline $\mathrm{Ja}$ & Eklem değişiklikleri \\
\hline $\mathrm{Jr}$ & Çatlak pürüzlülük \\
\hline $\mathrm{JV}$ & Hacimsel eklem sayısı \\
\hline $\mathrm{JW}$ & Çatlak su indirgeme faktörü \\
\hline $\mathrm{KB}$ & Kuzeybatı \\
\hline KDO & Kazı destek oranı \\
\hline $\mathrm{km}$ & Kilometre \\
\hline $\mathrm{km}^{2}$ & Kilometrekare \\
\hline $\mathrm{m}$ & Metre \\
\hline $\mathrm{m}^{2}$ & Metrekare \\
\hline $\mathrm{m}^{3}$ & Metreküp \\
\hline mak & Maksimum \\
\hline $\min$ & Minimum \\
\hline $\mathrm{m}_{\mathrm{i}}$ & Sağlam kayacın petrografik katsayısı \\
\hline $\mathrm{m}_{\mathrm{b}}$ & $\mathrm{m}_{\mathrm{i}}$ katsayısının indirgenmiş hali \\
\hline $\mathrm{mm}$ & Milimetre \\
\hline ort & Ortalama \\
\hline$p i^{c r}$ & Kritik destek basıncı \\
\hline$P_{i}^{c r}$ & Ölçekli kritik destek basıncı \\
\hline $\mathrm{Pi}$ & Destek basıncını \\
\hline $\mathrm{P}_{\mathrm{E}}$ & Tünel girişi \\
\hline $\mathrm{P}_{\mathrm{O}}$ & Tünel çıkışı \\
\hline Q & Barton kaya kütle sınıflama sistemi \\
\hline RMR & Rock mass rating (kaya kütlesi puanı) \\
\hline RMİ & Rock mass index (kaya kütlesi indeksi) \\
\hline RQD & Rock quality designation (kaya kalite göstergesi) \\
\hline
\end{tabular}


Türkiye’nin En Uzun Sulama Tüneli Suruç Tünelinde Geoteknik ve Tahkimat Tasarımlar

\begin{tabular}{|c|c|}
\hline $\mathrm{Rr}$ & Pürüzlülük derecesi \\
\hline $\mathrm{Rw}$ & Bozunma derecesi \\
\hline $\mathrm{Rf}$ & Dolgu derecesi \\
\hline $\mathrm{R}_{\mathrm{pl}}$ & Kırık bölgenin yarıçapı \\
\hline $\mathrm{S}$ & Tabakalaşma \\
\hline s & Taneler arası tutunma derecesi \\
\hline SCR & Yüzey koşulları derecesi \\
\hline Sx & x yönünde süreksizlik sayısı \\
\hline Sy & y yönünde süreksizlik sayısı \\
\hline $\mathrm{Sz}$ & z yönünde süreksizlik sayısı \\
\hline SR & Yapısal derece \\
\hline $\mathrm{S}_{0}$ & Ölçekli gerilme alanı \\
\hline SK & Sondaj kuyusu \\
\hline SRF & Gerilme indirgeme faktörü \\
\hline SP & Kötü derecelenmiş kum \\
\hline SW & İyi derecelenmiş kum \\
\hline TBM & Tunnel boring machine (tünel delme makinesi) \\
\hline TCR & Toplam karot verimi \\
\hline TKV & Karot verimi yüzdesi \\
\hline UCS & Tek eksenli basınç dayanımı \\
\hline$u_{r}^{e l}$ & Elastik yer değiştirme \\
\hline YASS & Yeraltı su seviyesi \\
\hline$\emptyset_{\mathrm{M}}$ & İçsel sürtünme açısı (marn) \\
\hline$\varnothing_{\mathrm{L}}$ & İçsel sürtünme açısı (kireçtaşı) \\
\hline$v$ & Poison Oranı \\
\hline$\sigma_{1}^{\prime}$ & Etkili büyük asal gerilme \\
\hline$\sigma_{3}^{\prime}$ & Etkili küçük gerilme \\
\hline$\sigma_{\mathrm{ci}}$ & Bozulmamış kaya tek eksenli basınç dayanımı (MPa) \\
\hline$\sigma c$ (kütle) & Kaya kütlesinin basınç dayanımı (MPa) \\
\hline$\gamma$ & Kaya kütlesinin birim hacim ağırlığı $\left(\mathrm{t} / \mathrm{m}^{3}\right)$ \\
\hline
\end{tabular}

\section{Teşekkür}

Yazarlar DSİ 15. Bölge Müdürlüğüne, İlci İnşaat A.Ş.'ye, Bar-Su ve Geotecna Progetti Srl. Şirketlerine, Editör ve hakem kuruluna teşekkürlerini sunar. 


\section{Kaynaklar}

[1] Bar-Su and Geotecna Progetti Srl. Engineering Companies, Suruç tunnel report, 2010.

[2] Diederichs, M.S., Hoek, E., DIPS 2.2. Advanced Version Computer Programme, Rock Engineering Group, Department of Civil Engineering, University of Toronto, 1989.

[3] Plaxis B.V., User manual for Plaxis 8.2. Computerlaan 14, 2628 XK Delft, The Netherlands, 2000.

[4] Ichikawa, K., Geological investigation of dams. Proc. of 2nd Asian Symposium on Engineering Geology and the Environment. Malaysian National Group, Bangi, Malaysia, s 1-57, 1999.

[5] ASTM D2487-11, Standard Practice for Classification of Soils for Engineering Purposes, Unified Soil Classification System (USCS). ASTM International, USA, 1984.

[6] AFAD (Afet ve Acil Durum Yönetimi), Deprem Dairesi Başkanlığı: http://www.deprem.gov.tr, (1996).

[7] ISRM (International Society for Rock Mechanics): The complete ISRM suggested methods rock characterization, testing and monitoring:1974-2006, Editors: R. Ulusay, J.A. Hudson, ISBN: 978-975-93675-4-1, Kozan Ofset, Ankara, Turkey, p 613 (2007).

[8] Ulusay, R., Sonmez, H.: Kaya kütlelerinin mühendislik özellikleri (in Turkish), TMMOB Jeoloji Mühendisleri Odası Yayınları, No: 60, Ankara (2002).

[9] Deere, D.U.: Geological consideration. In: Stagg, K.G., Zienkiewicz, O.C. (Eds.), Rock Mechanics in Engineering Practice. Wiley, London (1968).

[10] Bieniawski, Z.T.: Engineering classification of jointed rock masses. Trans. S. Afr. Inst. Civ. Eng. 15, 335-344 (1973).

[11] Barton, N.R., Lien, R., Lunde, J.: Engineering classification of rock masses for the design of tunnel support. Rock Mech. 4, 189- 239 (1974).

[12] Palmstrom, A.: RMi - a rock mass characterization system for rock engineering purposes. PhD Thesis, Oslo University, Norway. p 400 (1995).

[13] Hoek, E., Brown, E.T.: Practical estimates of rock mass strength. Int. J. Rock Mech. Min. Sci. Geomech. Abstr. 27 (3), 227- 229 (1997).

[14] Bieniawski, Z.T.: Engineering Rock Mass Classifications. Wiley, New York. pp 251 (1989).

[15] Grimstad, E., Barton, N.: Updating the Q-system for NMT. Proc. Int. Symp. on Sprayed Concrete, Fagernes, Norway, Norwegian Concrete Association, Oslo, p 20 (1993).

[16] Hoek, E., Marinos, P., Benissi, M.: Applicability of the geological strength index (GSI) classification for very weak and sheared rock masses: the case of the Athens 
Türkiye’nin En Uzun Sulama Tüneli Suruç Tünelinde Geoteknik ve Tahkimat Tasarımlar

schist formation. Bulletin of Engineering Geology and the Environment 57, 151-160 (1998).

[17] Sonmez, H., Ulusay, R.: Modifications to the geological strength index (GSI) and their applicability to stability of slopes. International Journal of Rock Mechanics and Mining Sciences 36 (6), 219-233 (1999).

[18] Sonmez, H., Ulusay, R.: A discussion on the Hoek -Brown failure criterion and suggested modifications to the criterion verified by slope stability case studies. Yerbilimleri 26, 77-99 (2002).

[19] Goel, R.K., Jethwa, J.L., Paithankar, A.G.: Indian experiences with Q and RMR systems. Tunn. Undergr. Space Technol. 10 (1), 97- 109 (1995).

[20] Hoek, E., Kaiser, P.K., Bawden, W.F.: Support of underground excavations in hard rock. Balkema, Roterdam, Brookfield, p 213 (1995).

[21] Barton, N.: Some new Q-value correlations to assist in site characterization and tunnel design. Int. J. Rock Mech. Min. Sci. 39 (1), 185-216 (2002).

[22] Singh, B., Viladkar, M.N., Samadhiya, N.K., Mehrota, V.K.: Rock mass strength parameters mobilized in tunnels. Tunn. Undergr. Space Technol. 12 (1), 47-54 (1997).

[23] Palmstrom, A.: Recent developments in rock support estimates by the RMi. J. Rock Mech. Tunn. Technol. 6 (1), 1-19 (2000).

[24] Palmstrom, A.: Characterizing rock masses by the RMI for use in practical rock engineering: Part 1: The development of the Rock Mass Index (RMI). Tunn. Undergr. Space Technol. 11 (2), 175-188 (1996).

[25] Ramamurthy, T.: Stability of rock mass. Indian Geotechnical Journal, 1-74 (1986).

[26] Goel, R.K.: Correlations for predicting support pressures and closures in tunnels. $\mathrm{PhD}$ Thesis, Nagpur University, Nagpur, India, p 308 (1994).

[27] Kalamaris, G.S., Bieniawski, Z.T.: A rock mass strength concept for coal incorporating the effect of time. Proceedings of the Eighth International Congress on Rock Mechanics, vol. 1. Balkema, Rotterdam, 295-302 (1995).

[28] Bhasin, R., Grimstad, E.: The use of stress-strength relationships in the assessment of tunnel stability. Tunn. Undergr. Space Technol. 11 (1), 93-98 (1996).

[29] Aydan, O., Ulusay, R. and Kawamoto, T.: Assessment of rock mass strength for underground excavations. International Journal of Rock Mechanics and Mining Science 34 (3/4), 777-786 (1997).

[30] Sheorey, P.R.: Empirical Rock Failure Criteria. Balkema, Rotterdam (1997).

[31] Trueman, R.: An evaluation of strata support techniques in dual life gateroads. PhD Thesis, University of Wales, Cardiff. In Read, S.A.L., Richards, L.R., and Perrin, N.D., 1999. Applicability of the Hoek-Brown failure criterion to New Zealand greywacke rocks. Proceeding 9th International Society for Rock Mechanics Congress, Paris, 2, 655-660 (1998). 
[32] Aydan, O., Dalgic, S.: Prediction of deformation behavior of 3 lanes Bolu tunnels through squeezing rocks of North Anatolian Fault Zone (NAFZ). Proceedings of the Regional Symposium on Sedimentary Rock Engineering, Taipei, 228-233 (1998).

[33] Barton, N.: TBM Tunnelling in Jointed and Faulted Rock. Rotterdam, Balkema, pp 169 (2000).

[34] Bieniawski, Z.T.: Determining rock mass deformability: experience from case histories. Int. J. Rock Mech. Min. Sci. Geomech Abstr. 15, 237-247 (1978).

[35] Serafim, J.L., Pereira, J.P.: Considerations of the geomechanics classification of Bieniawski. Proceedings International Symposium Engineering Geology and Underground Construction, vol. 1. Balkema, Rotterdam, 1133-1142 (1983).

[36] Nicholson, G.A., Bieniawski, Z.T.: A non-linear deformation modulus based on rock mass classification. Int. J. Mining and Geological Engineering 8, 181-202 (1990).

[37] Verman, M.K.: Rock mass-tunnel support interaction analysis, PhD Thesis, University of Roorkee, Roorkee, India (1993).

[38] Mitri, H.S., Edrissi, R., Henning, J.: Finite element modeling of cable-bolted slopes in hard rock underground mines. SME Annual Meeting 14-17 February, New Mexico. SME, Albuquerque, 94-116 (1994).

[39] Hoek, E., Brown, E.T.: Practical estimates of rock mass strength. Int. J. Rock Mech. Min. Sci. 34 (8), 1165- 1186 (1998).

[40] Read, S.A.L., Richards, L.R., Perrin, N.D.: Applicability of the Hoek-Brown failure criterion to New Zealand greywacke rocks. Proceeding 9th International Society for Rock Mechanics Congress, Paris, vol. 2, 655- 660 (1999).

[41] Hoek, E., Diederichs, M.S.: Empirical estimation of rock mass modulus. International Journal of Rock Mechanics and Mining Sciences 43 (2), 203-215 (2006).

[42] Unal, E.: Design Guidelines and Roof Control Standards for Coal Mine Roofs. Ph.D. Thesis, Pennsylvania State University (Reference Bieniawski, Z.T., 1984, Rock Mechanics in Mining and Tunnelling, p. 113, Rotterdam: A. A. Balkema (1983).

[43] Fenner, R.: Untersuchungen zur Erkenntnis des Gebirgsdruckes. Gluckauf, 74, 681695 and $705-715$ (1938).

[44] Carranza-Torres, C., Fairhurst, C.: The elasto-plastic response of underground excavations in rock masses that satisfy the Hoek-Brown failure criterion. Int. J. Rock Mech. Min. Sci. 36, 777-809 (1999).

[45] Carranza-Torres, C., Fairhurst, C.: Application of the convergence-confinement method of tunnel design to rock masses that satisfy the Hoek-Brown failure criterion. Tunn. Undergr. Space Technol. 15 (2), 187-213 (2000).

[46] Basarir, H., Ozsan, A., Karakus, M.: Analysis of support requirements for a shallow diversion tunnel at Guledar dam site, Turkey. Eng. Geol. 81, 131-145 (2005).

[47] Basarir, H.: Engineering geological studies and tunnel support design at Sulakyurt dam site, Turkey. Eng. Geol. 86, 225-237 (2006). 
Türkiye’nin En Uzun Sulama Tüneli Suruç Tünelinde Geoteknik ve Tahkimat Tasarımlar

[48] Hoek, E., Marinos, P.: Predicting tunnel squeezing. Tunnels and Tunnelling International. Part 1 -November 2000, Part 2 December 2000 (2000).

[49] Çubuk, M.K., Öztürk, E.A., Hatipoğlu, S., Sinoplu, M.Z.: Türkiye'deki Karayolu Tünellerinde Trafik Güvenliği. İMO Teknik Dergi 3, 4471-4486 (2008). 